\title{
检测活性氮/活性氧的分子苂光探针
}

\author{
矫春鹏 $a, b, c, d$ 刘媛媛 $a, b, c, d$ 路文娟 ${ }^{a, b, c, d}$ \\ 张平平 $a, b, c, d$ 王延风 $*, a, b, c, d$ \\ $\left({ }^{a}\right.$ 济南大学山东省医学科学院医学与生命科学学院 济南 250062) \\ $\left({ }^{b}\right.$ 山东省医学科学院药物研究所 济南 250062) \\ ( ${ }^{c}$ 国家卫生部生物技术药物重点实验室 济南 250062) \\ ( $d$ 山东省罕少见病重点实验室 济南 250062)
}

\begin{abstract}
摘要 活性氮和活性氧是具有强生物活性的化学物质. 在人体细胞中, 由于酶促或非酶促过程均可生成过氧化物, 该 物种的异常水平会引起氧化损伤与衰老和各种疾病，如心血管疾病、神经性疾病、阿尔茨海默病、帕金森病甚至癌症. 因此, 发展选择性识别和高灵敏度的分子荧光探针, 实现活性氮或活性氧的有效检测具有重要意义. 分子荧光探针检 测法与成像技术具有灵敏度高、选择性强、损伤性小和细胞相容性好等优点, 并在阐述活性氮和活性氧的病理生理过 程中起到重要作用, 在生物和医学等领域应用广泛. 然而, 由于活性氮和活性氧自身的特殊性而存在许多难题, 例如 反应活性高、存在周期短等一直困扰研究人员. 着重综述了近年来发展的分子荧光探针用于活性氮和活性氧的检测及 细胞成像工作的研究进展，提出进一步构建新型分子苂光探针用于活性氮和活性氧检测面临的挑战、未来发展方向及 展望.
\end{abstract}

关键词 活性氮; 活性氧; 苂光探针; 苂光成像

\section{Molecular Fluorescence Probe for Detecting Reactive Nitrogen/Reactive Oxygen}

\author{
Jiao, Chunpeng ${ }^{a, b, c, d}$ \\ Liu, Yuanyuan ${ }^{a, b, c, d}$ \\ $\mathrm{Lu}$, Wenjuan $^{a, b, c, d}$ \\ Zhang, Pingping $a, b, c, d$ \\ Wang, Yanfeng ${ }^{*, a, b, c, d}$ \\ ( ${ }^{a}$ School of Medicine and Life Sciences, University of Jinan-Shandong Academy of Medical Sciences, Jinan 250062) \\ ( ${ }^{b}$ Institute of Materia Medica Shandong Academy of Medical Sciences, Jinan 250062) \\ ( ${ }^{c}$ Key Laboratory for Biotech-Drugs Ministry of Health, Jinan 250062) \\ ( ${ }^{d}$ Key Laboratory of Rare and Uncommon Diseases of Shandong Province, Jinan 250062)
}

\begin{abstract}
Reactive nitrogen and reactive oxygen are chemical substances with strong biological activity. In human cells, peroxides can be generated due to enzymatic or non-enzymatic processes. Abnormal levels of peroxide can cause oxidative damage and aging and various diseases such as cardiovascular disease, neurological diseases, Alzheimer's disease, Parkinson's disease and even cancer. In order to effectively cure these diseases, health workers must find the source of the problem. Currently, there is no better way to detect reactive oxygen species and reactive nitrogen. Fluorescence spectrometry in recent years becomes the preferred method for the majority of researchers for detecting active oxygen and reactive nitrogen. Therefore, the development of selective recognition and high sensitivity molecular fluorescent probes to achieve effective detection of reactive nitrogen and reactive oxygen species is of great significance. On one hand, molecular fluorescent probe detecting and imaging technology has excellent characteristics such as high sensitivity, strong selectivity, small damage and good cell compatibility. On the other hand, fluorescent probes play an important role in the pathophysiological process of reactive nitrogen and reactive oxygen species. Therefore, the fluorescent probe method is widely used in the fields of biology and medicine. However, due to the inherent specificity of reactive nitrogen and reactive oxygen species, it has become an urgent problem for researchers, such as high reactivity, short cycle, etc. In order to overcome the shortcomings of fluorescent probe
\end{abstract}

* Corresponding author. E-mail: wyfshiwoya@126.com

Received October 12, 2018; revised November 2, 2018; published online November 30, 2018.

Project supported by the National Natural Science Foundation of China (No. 21305079).

国家自然科学基金(No. 21305079)资助项目. 
analysis, researchers are constantly striving to find better active fluorescent probes for the detection of reactive nitrogen and reactive oxygen species. Recent evolutions in the development of molecular fluorescent probes for the detection of active nitrogen and reactive oxygen species and cell imaging work are reviewed. Finally, a new type of molecular fluorescent probe is proposed to be used for the challenge of active nitrogen and active oxygen detection, and the future development direction and prospect.

Keywords reactive nitrogen species; reactive oxygen species; fluorescence probe; fluorescence imaging

生物机体在含氧新陈代谢过程中会产生多种自由 基，活性氮物种(Reactive nitrogen species, RNS)和活性 氧物种(Reactive oxygen species, ROS)便是其中重要的 两类 ${ }^{[1]}$. RNS 主要是一氧化氮(NO)与包括 ROS 在内的活 性物质相互作用衍生出的一系列具有高度活性的自由 基和硝基类化合物, 主要包括一氧化氮( $\mathrm{NO}$ )、二氧化氮 $\left(\mathrm{NO}_{2}\right)$ 、次硝酸 $(\mathrm{HNO})$ 、亚硝酸根离子 $\left(\mathrm{NO}_{2}^{-}\right)$和过氧化 亚硝酰阴离子 $\left(\mathrm{ONOO}^{-}\right)^{-}$等 $^{[2]}$. RNS 在自然界分布广泛, 人体中活性氮物种对于癌症具有双向作用, 一方面通过 产生亚硝胺类致癌物破坏 DNA 并抑制 DNA 修复系统 引发癌症, 另一方面则具有阻止癌细胞转移和抑制分化 的作用 ${ }^{[3,4]}$. 正常水平的 RNS 对人体生理机能具有至关 重要的意义, 细胞信号的传导、机体物质合成代谢与能 量转换等都需要 RNS 的介导, 一旦水平失衡便会引起 人体机能紊乱, 诱发各种疾病 ${ }^{[5]}$. ROS 是机体在有氧环 境下的代谢副产品, 氧被过氧化酶催化形成过氧化离子 或超氧化离子, 在细胞中经过不断转化最后可形成化学 反应活跃的氧自由基, 主要包括氧离子、过氧化物 $\left(\mathrm{H}_{2} \mathrm{O}_{2}, \mathrm{HClO} \text { 等)和含氧自由基( } \mathrm{HO} \text { •等 }\right)^{[6]}$. $\mathrm{ROS}$ 对机体也 具有双重性. 优点: 少量 ROS 可激活环氧化酶和脂氧合 酶活性. 而过量 ROS 则起到抑制作用; 巨噬细胞在吞噬 异物过程中生成大量氧自由基和过氧化氢, 并摧毁异物 或细菌. 可见 ROS 与某些机体生理活性物质的调控和 免疫过程有关. 弊端: 像金属被氧化物腐蚀一样, 机体 内 ROS 过度活跃则会起到破坏作用, 如共价结合, 改变 多不饱和脂肪酸与蛋白质的比例而干扰膜的转运功能, 加速人体衰老及细胞损坏 ${ }^{[7]}$. 因此, 探索环境及机体中 活性氮和活性氧的含量、分布及作用机制成为目前重要 的研究领域.

检测活性氮和活性氧的方法有比色法、质谱法、电 化学分析法、电子自旋共振波谱法、紫外可见光谱分析 法和苂光分析法等 ${ }^{[8]}$. 其中, 苂光分析法具有灵敏度高、 生物相容性好、易于化学和生物学修饰等优点, 备受分 析化学、生物学和医学等领域的关注, 尤其是近年来被 广泛应用于活性氮和活性氧检测, 大大推进人们对机体 活性氮和活性氧的研究进程.

近 10 年来, 活性氮和活性氧及其衍生物的苂光可 视化检测一直是环境、生物和医学领域研究的热点和重 点, 国内外研究者对活性氮和活性氧的分子苂光探针的 设计与合成方法不断地被创新和改造并取得众多成效.
本文主要综述近 5 年来在活性氮和活性氧方面的分子荧 光探针的研究进展.

\section{1 用于检测活性氮的荧光探针}

\section{1 用于一氧化氮(NO)检测的苂光探针}

一氧化氮(NO)是一种具有高度活性的自由基气体, 其作为一种信号因子无处不在，在生物生理系统的稳态 调节过程中扮演重要角色，例如: 神经系统方面，作为 信号传导因子，参与神经递质的释放传送; 心血管方面， 可以促使血管平滑肌舒张减压; 在合适的作用时间和位 点进行诱导，具有良好的抗病毒、抗菌、抗肿瘤等免疫 功效; 随着近年来的研究表明, NO 在抗细胞凋亡和衰 老等方面也具有一定效果. 异常的 NO 水平，则会打破 原有生理平衡, 引起多种疾病, 例如阿尔兹海默综合症 和帕金森综合症等疾病 ${ }^{[9,10]}$.

近年来, 涌现出一系列利用邻苯二胺与 NO 成五元 环抑制光诱导电子转移(Photoinduced electron transfer, PET)机理从而改变苂光团母核的苂光探针 ${ }^{[11]}$. 该类探 针中荧光团受到激发后基态电子跃迁到高能级从而产 生空轨道, 邻苯二胺基团将处于最高能级的电子转移到 该空轨道中，这就导致荧光团中被激发的电子无法直接 跃迁回基态发射荧光，从而导致了苂光的淬灭(Eq. 1). 江华和李国平课题组 ${ }^{[12]}$ 介绍了一种以 2-乙酰基-6-二甲 基氨基䒬为苂光团，用于细胞中 $\mathrm{NO}$ 检测的双光子苂光 探针 1. 在与 $\mathrm{NO}$ 接触后, 邻苯二胺结构被氧化, PET 过 程受到抑制, $546 \mathrm{~nm}$ 处苂光强度增强, 其紫外吸收波长 从 $390 \mathrm{~nm}$ 蓝移至 $358 \mathrm{~nm}$, 并被成功应用于细胞 NIH3T3 成像. 为减少细胞损伤并将其应用于人体检测，刘志宏 课题组 ${ }^{[13]}$ 设计并合成了一种基于喹啉的近红外双光子 荧光探针 2, 并用于活细胞和组织中的 NO 检测. 该探 针在 $810 \mathrm{~nm}$ 激发波长下与 $\mathrm{NO}$ 接触后, 邻苯二胺中的两 个氨基与 $\mathrm{NO}$ 反应形成五元杂环，抑制了 PET 过程，使 得在 $810 \mathrm{~nm}$ 双光子激发波长下 $535 \mathrm{~nm}$ 处强苂光强度逐 渐增强，同时由于探针具有高选择性、低细胞毒性和 $\mathrm{pH}$ 不敏感性等优点，可以应用于 $90 \sim 180 \mu \mathrm{m}$ 深度的活体 组织细胞中的 $\mathrm{NO}$ 检测. 同时, 探针 $\mathbf{3}$ 是刘海英课题 组 ${ }^{[14]}$ 为了更好地适应水性检测环境设计并合成的一个 基于硼二吡咯烷(BODIPY)类衍生物的高水溶性荧光探 针，侧链位置三甘醇甲基醚的引入大大提高了该化合物 
的水溶性, 2,6-位引入的富电子邻苯二胺作为响应基团. 由于发生邻苯二胺向 BODIPY 的 PET 作用, BODIPY 染 料的荧光发生明显的猝灭; 当进行细胞中 NO 检测时, 邻苯二胺结构被氧化成五元杂环, PET 过程被阻止, 苂 光恢复, $557 \mathrm{~nm}$ 处苂光增强. 该探针具有优异的水溶 性、膜透性和与活细胞的相容性, 并成功检测到 RAW 264.7 中的内源性 NO.
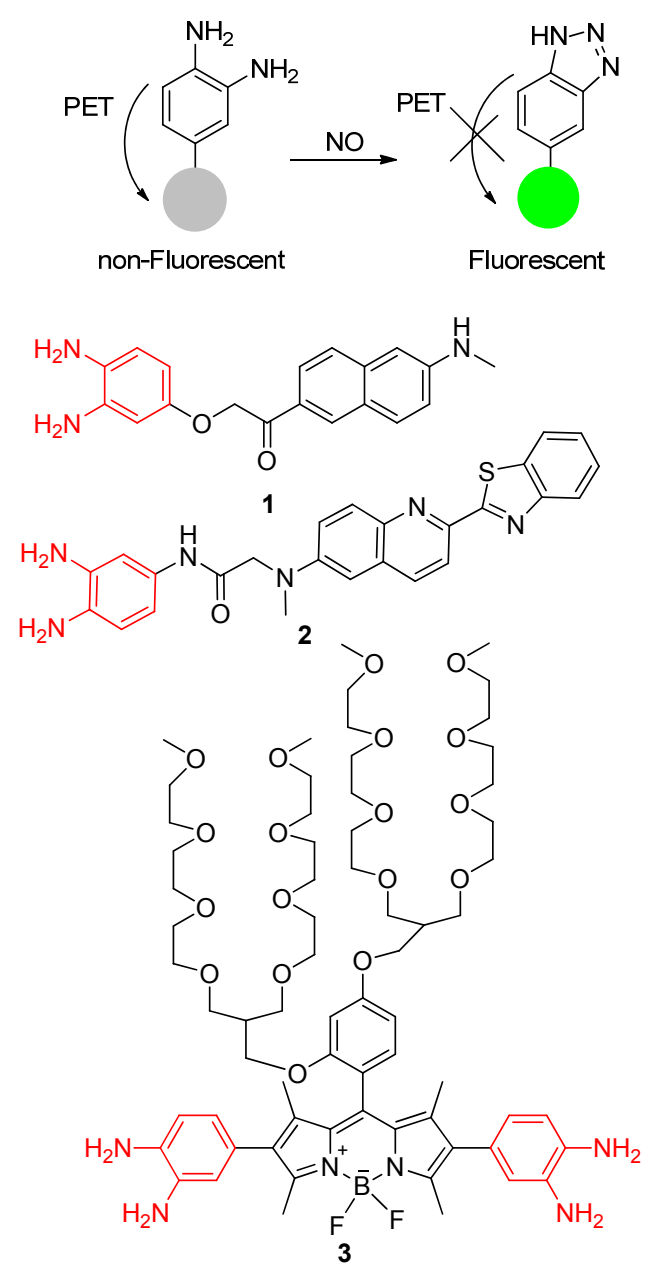

随后, 崔京南课题组 ${ }^{[15]}$ 基于 PET 与分子内电荷转 移(ICT)效应设计并合成一个用于 NO 检测的菼光探针 4. 探针 4 以菜酰亚胺为荧光团, 在 3,4-位引入氨基响应 基团, 邻位两个氨基与 NO 选择性反应生成三坐环后, 发射波长发生蓝移, 在生理条件下生成 DAN-T 的三唑 化物形式，抑制了 1,8-菜二甲酰亚胺的 3-氨基的 PET 效 应与 4-氨基的 ICT 效应, $454 \mathrm{~nm}$ 处苂光强度增强, 并应 用于细胞 HT29 成像中. 与探针 4 的 PET 和 ICT 原理一 样, 王丽秋课题组 ${ }^{[16]}$ 设计并合成一个靶向溶酶体检测 $\mathrm{NO}$ 的分子苂光探针 $\mathbf{5}$. 该探针同样以荎酰亚胺为荧光 才, 引入溶酶体目标基团 4-(2-氨基乙基)-吗啉, 生理 $\mathrm{pH}$ 下稳定性良好, 在与 $\mathrm{NO}$ 反应后形成大共轭体系, 荧光 量子产率提高, $454 \mathrm{~nm}$ 处强度增强, 具有高灵敏度(4.57 $\left.\mu \mathrm{mol} \cdot \mathrm{L}^{-1}\right)$.<smiles>CCCCN1C(=O)c2cccc3c(N)c(N)cc(c23)C1=O</smiles>

与前 5 个探针机理不同, 王云铭课题组 ${ }^{[17]}$ 报道了一 个利用罗丹明内酰胺环的开启用于 NO 检测的探针 $\mathbf{6}$, 选用罗丹明作为荧光团，水合肼氨基与罗丹明羧基反应 生成内酰胺环，当与 NO 反应后，内酰胺环打开显现罗 丹明苂光, $580 \mathrm{~nm}$ 处苂光强度增强(Eq. 2). 2013 年，肖义 课题组 ${ }^{[18]}$ 利用相同机理并引进三苯基膦靶向线粒体合 成了分子苂光探针 7. 该探针具有选择性高、检测限低 $\left(4.0 \mathrm{nmol} \cdot \mathrm{L}^{-1}\right)$ 、细胞毒性低和靶向性强等优点, 并成功 应用于活细胞 MCF-7 和 RAW 264.7 线粒体中 NO 的检 测(Eq. 3).
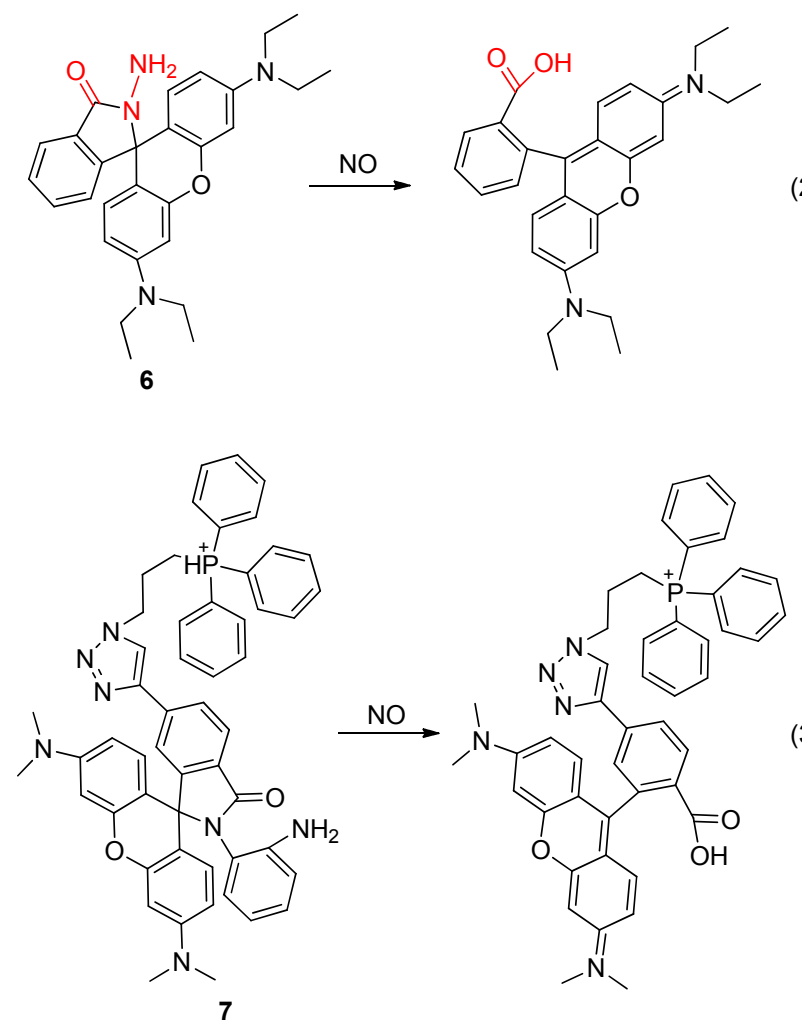

(3)

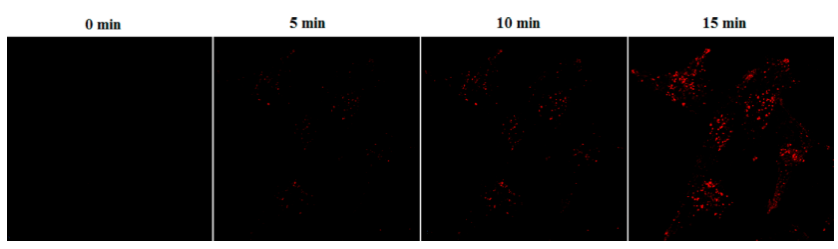

图 1 探针 7 与 $\mathrm{NO}$ 反应细胞成像

Figure 1 Imaging of probe 7 and NO reactive cells 
过渡金属由于其顺磁性对处于激发态荧光团具有 淬灭作用被研究者所关注, 基于过渡金属络合物的荧光 团被设计并研究. NO 可与过渡金属生成新金属亚硝酰 基络合化合物，金属顺磁性被破坏或者与荧光团竞争夺 去过渡金属, 荧光团荧光恢复 ${ }^{[19]}$. Ali 课题组 ${ }^{[20]}$ 设计并合 成出探针 8 用于 $\mathrm{NO}$ 检测, 该探针是基于丹磺酰基引入 不饱和含 $\mathrm{N}$ 杂原子环与顺磁性 $\mathrm{Cu}^{2+}$ 络合淬灭苂光, 在 与 $\mathrm{NO}$ 反应后, 络合金属由 $\mathrm{Cu}^{2+}$ 到 $\mathrm{Cu}^{+}$, 顺磁性被破坏, $532 \mathrm{~nm}$ 处苂光团苂光强度增强, 并成功用于 HeLa 细胞 $\mathrm{NO}$ 检测成像(Eq. 4). 与 Ali 课题组工作相同, 均利用金 属顺磁性的淬灭效果, Mondal 课题组 ${ }^{[21]}$ 报道了探针 9. 该探针具有高水溶性和高选择性, 当与 $\mathrm{NO}$ 反应后, 金 属离子被剥夺, 顺磁性干扰消除, 荧光团 $400 \mathrm{~nm}$ 处苂光 强度增强, 并被成功用于 SKN-SH 细胞检测 NO (Eq. 5).
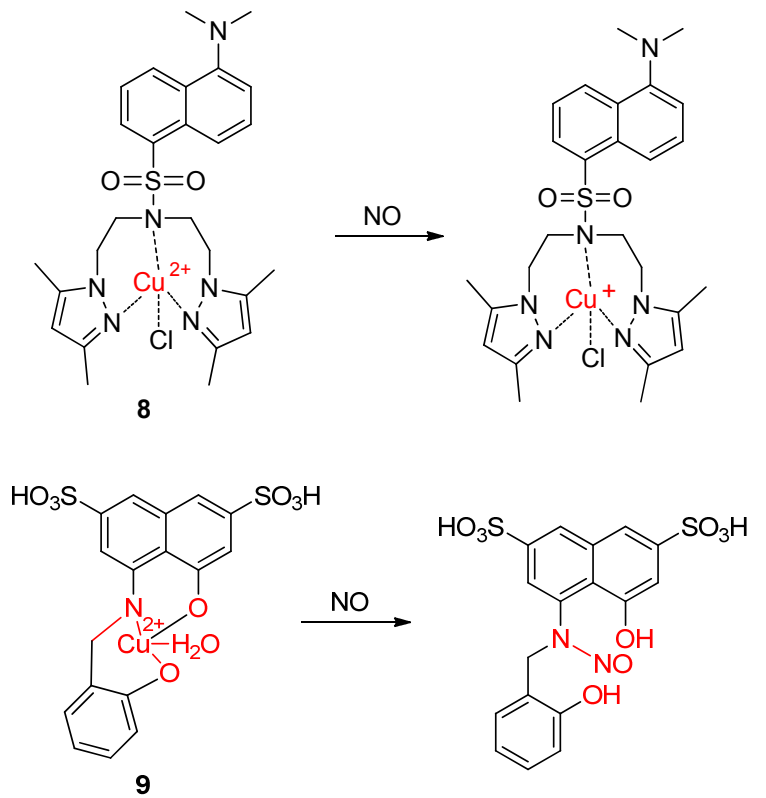

(5)

基于 NO 重氮化反应，Yoon 课题组 ${ }^{[22]}$ 报道了探针 10, 该探针由二甲氨基苯和苯并噻吩通过 4-氨基甲苯的 2,5 位连接, 在与 $\mathrm{NO}$ 反应后苯胺上氨基发生重氮化反 应与二甲氨基苯 4 位连接形成大 $\pi$ 体系, 形成比率型荧 光探针, 二甲氨基苯形成的大 $\pi$ 体系在 $470 \mathrm{~nm}$ 处的苂光 增强, 苯并噻唑在 $560 \mathrm{~nm}$ 处的苂光减弱(Eq. 6). 相比其 它 $\mathrm{H}_{2} \mathrm{O}_{2}, \mathrm{ONOO}^{-}, \mathrm{ClO}^{-}, \cdot \mathrm{OH}, \mathrm{NO}_{2}^{-}, \mathrm{NO}_{3}^{-}$等活性氮、 活性氧物质具有高选择性, 成功应用于 HeLa 细胞检测 $\mathrm{NO}$ 并成像. 与 Yoon 课题组相似, 宋钦华课题组 ${ }^{[23]}$ 设计 并合成双光子荧光探针 11, 可选择性快速检测活体细 胞和组织切片中的 NO, 该探针以 5-氨基喹啉作为荧光 团前体, 6-位引入二甲氨基苯作为响应位点, 与 $\mathrm{NO}$ 反应 后发生重氮化反应, $540 \mathrm{~nm}$ 处苂光强度增强, 具有低检 测限 $\left(15 \mathrm{nmol} \cdot \mathrm{L}^{-1}\right)$ 和高灵敏度等优点, 成功被用于 RAW 264.7 细胞检测 NO 成像(Eq. 7).
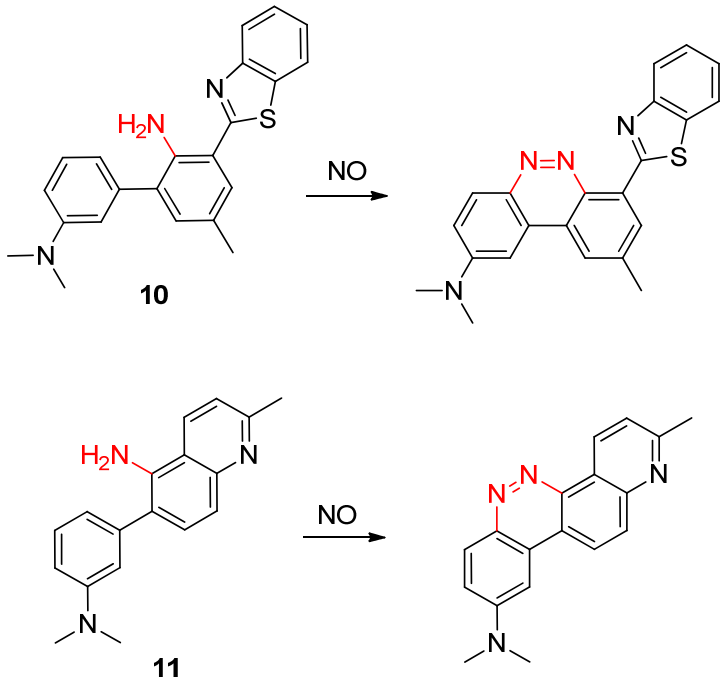

科学研究发现 5-甲基胞嘧啶、鸟嘌呤、腺嘌呤中的 氨基可被 NO 诱导脱落. 基于 NO 的这一特殊机理, Luis 和 Galindo 课题组 ${ }^{[24]}$ 报道了基于吡喃阳离子以邻羟基氨 基为基础的探针 12 , 在与 $\mathrm{NO}$ 反应后，苯环上氨基脱落， $550 \mathrm{~nm}$ 处苂光强度增强, 检测限低 $\left(2.1 \mu \mathrm{mol} \cdot \mathrm{L}^{-1}\right)$, 相比 $\mathrm{H}_{2} \mathrm{O}_{2}, \mathrm{ONOO}^{-}, \mathrm{ClO}^{-}, \cdot \mathrm{OH}, \mathrm{NO}_{2}^{-}, \mathrm{NO}_{3}^{-}, \mathrm{HNO}, \mathrm{O}_{2}$ 等物 质具有高选择性, 并被成功用于 RAW 264.7 细胞检测 NO 及成像(Eq. 8).<smiles>COc1ccc(-c2cc(-c3cc(-c4ccc(OC)cc4)cc(-c4ccc(OC)c(-c5ccc(OC)cc5)c4)c3)cc(-c3ccc(OC)c(OC)c3)c2)cc1</smiles>

\section{2 用于 HNO 检测的荧光探针}

次硝酸 $(\mathrm{HNO})$ 被认为是 $\mathrm{NO}$ 被线粒体黄嘌呤氧化酶 和细胞色素 $\mathrm{C}$ 还原的产物, 具有一定的药理作用, 例如: 对心力衰竭和钻通道具有正向调节作用, 对肿瘤细胞的 生长繁殖具有抑制作用，同时也是有效的血小板聚集抑 制剂. 目前用于 HNO 检测的探针响应机理主要有两种 类型.

第一种类型为(二苯基膦基)苯酸盐作为反应基团: 当与 $\mathrm{HNO}$ 结合以后，(二苯基膦基)苯酸盐通过 Staudinger ligation(施陶丁格反应)转化为羟基, 此时通 过螺内开环机制或者 ICT(分子内电荷转移)机制促使荧 光团的苂光恢复 (Scheme 1). 自第一例此种类型的 HNO 荧光出现以后 ${ }^{[25]}$, 大量的该类型探针涌现. 2014 年谭蔚 泓课题组 ${ }^{[26]}$ 报道了一种以香豆素类为荧光团用于对水 溶液和血清中硝酰基检测的探针 13. 该探针在香豆素 
7-位羟基引进二苯基膦苯甲酸酯作为 HNO 的检测基团, 在与 HNO 接触后 7-羟基香豆素苂光团被释放, $450 \mathrm{~nm}$ 处苂光强度增强. 该探针具有选择性高、灵敏度高、细 胞毒性低、检测限低 $\left(20 \mathrm{nmol} \cdot \mathrm{L}^{-1}\right)$ 及不受其他生物还原 剂影响等优点, 对血清中 HNO 的定量检测结果满意, 有利于复杂生物样品中 HNO 的直接定量检测, 具有实 用价值. King 课题组 ${ }^{[27]}$ 合成了以苂光素为苂光团的 HNO 探针 14, 该探针能够用于 Hela 细胞内 HNO 的共 聚焦成像.

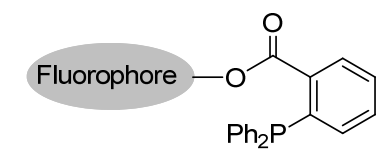

Fluorophore-off

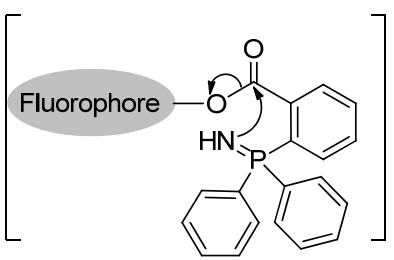

图式 1 苯酸盐作为反应基团

Scheme 1 Diphenylphosphino groups as reactive groups<smiles>O=C(Oc1ccc2ccc(=O)oc2c1)c1ccccc1P</smiles>

13<smiles>COc1ccc2c(c1)Oc1cc(CC(=O)c3ccccc3PP)ccc1C21OC(=O)c2ccccc21</smiles>

14
为了提高探针的选择性, 2015 年朱宝存和张晓玲课 题组 ${ }^{[28]}$ 设计并合成了一种用于 HNO 检测的苂光探针 15. 该探针以 2-(二苯基膦)苯甲酸酯作为响应基团, 即 使在谷胱甘肽、硫化氢和抗坏血酸等生物还原剂存在下 仍具有较高的 HNO 选择性, 2-(2-羟基苯基)苯并噻唑作 为苂光团显色, 在与 HNO 接触后, 探针可快速响应, 紫 外吸收波长红移, $495 \mathrm{~nm}$ 处苂光强度增强, 检出限为 50 $\mathrm{nmol} \cdot \mathrm{L}^{-1}$, 并用于 HeLa 细胞检测 HNO. 2016 年杨小峰 课题组 ${ }^{[29]}$ 设计了一种基于花青素骨架的线粒体靶向 NIR 苂光探针 16. 该探针以亲脂吲哚阳离子为线粒体靶 向位点, 在与 HNO 反应后 $727 \mathrm{~nm}$ 处荧光出现, 该探针 对 HNO 有较高的敏感性和选择性. 细胞成像和共定位 实验证明该探针适用于活细胞线粒体中 HNO 的可视化 检测(图 2). 林伟英课题组 ${ }^{[30]}$ 设计了三种均具有良好选 择性、高敏感性以及低细胞毒性的探针 $17 \mathrm{~A} \sim 17 \mathrm{C}$. 三 种化合物除可以单独使用外, 还可以混合使用, 当三种
化合物共同培养细胞时，在 HNO 存在下可以观察到从 绿色到彩色的多种颜色变化, 这种多种颜色变化使观察 更加精准，且化合物 $17 \mathrm{C}$ 还可以用于小鼠体内成像. 2017 年 Thomas 课题组 ${ }^{[31]}$ 报道了一种基于 BODIPY 的苂 光探针 18. 该探针具有高灵敏度、高选择性、低细胞毒 性等优点, 已用于检测水溶液和活 264.7 细胞中的 HNO. 2018 年彭孝军课题 ${ }^{[32]}$ 以 6-差基喹啉-2-苯并噻唑的衍生 物合成了双光子苂光探针，该探针能够检测 RAW 264.7 细胞外生型及 Hela 内生型 HNO, 在病理学及生理学研 究方面将是很好的工具. 除此之外, 还有多个文献报道 了相关的研究工作 ${ }^{[33 \sim 35]}$.

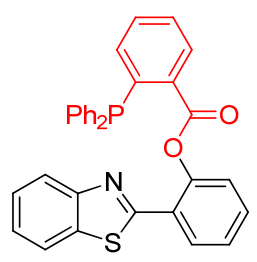

15

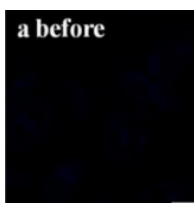

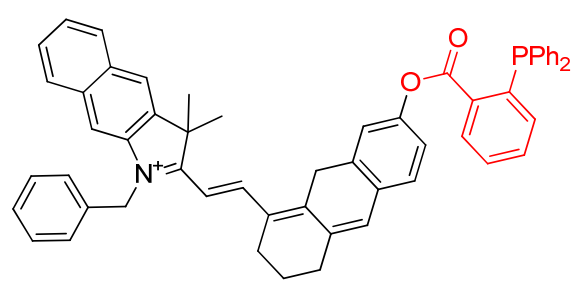

16
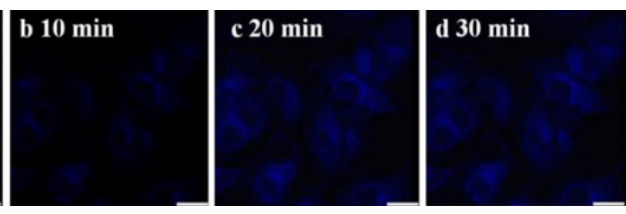

图 2 探针 16 与 $\mathrm{HNO}$ 反应细胞成像

Figure 2 Imaging of probe $\mathbf{1 6}$ with HNO-reactive cells<smiles>O=C(Oc1ccc2c(c1)OC(=O)C(c1nc3ccccc3s1)C2)c1ccccc1P</smiles>

$17 A$<smiles>Cc1c(OC(=O)c2ccccc2P)ccc2nc3c4ccccc4c(=O)cc-3oc12</smiles>

17B
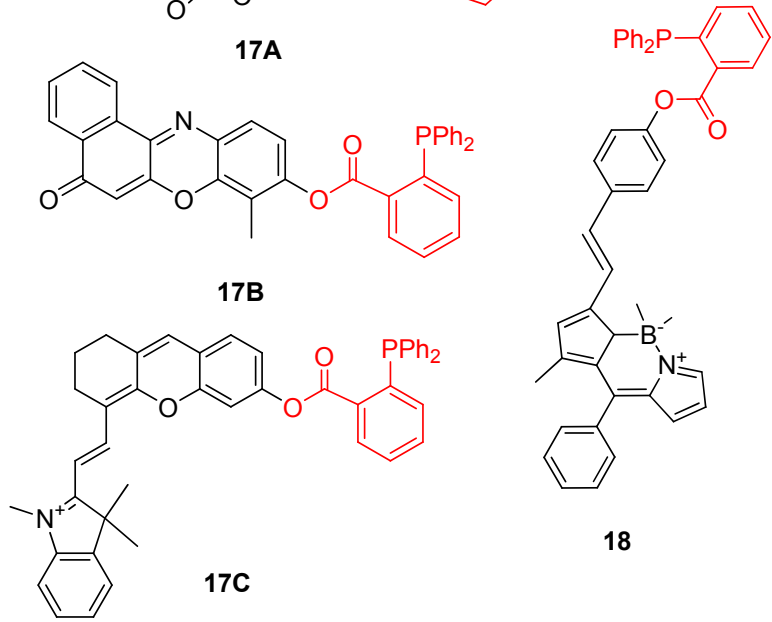

18
第二类为基于铜络合物的荧光探针. 该类探针与 $\mathrm{HNO}$ 反应前, 发生荧光团到 $\mathrm{Cu}(\mathrm{II})$ 成单电子 $\mathrm{d}$ 轨道的 PET, 致使苂光团的苂光淬灭. 与 HNO 反应后，二价铜 离子被还原为一价, $\mathrm{d}$ 轨道全部配对, PET 作用受到限制, 苂光重新恢复(Eq. 9). 


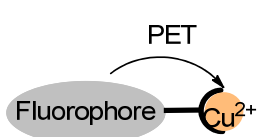

Fluorophore-off
$\mathrm{HNO}$

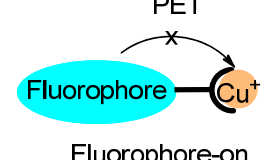

(9)

2010 年 Lippard 等 ${ }^{[36]}$ 首次报道了基于该机理的荧光 探针. 在该开创性的工作之后, Lippard 课题组 ${ }^{[37]}$ 于 2014 年首次合成一例近红外 HNO 荧光探针 19, 该探针对生 物样品具有低的光损伤、低背景噪声以及较强的组织穿 透力. 该化合物以 2-羟基氧杂蒽作为苂光团, 与 $\mathrm{HNO}$ 结合后 $715 \mathrm{~nm}$ 苂光强度增大 5 倍; 与硫醇及其他活性 氮、活性氧相比, 该探针对 HNO 有很好的选择性. 该课 题组 ${ }^{[38]}$ 于 2015 年以四甲基罗丹明为苂光团合成了探针 20, 当探针与过量的 AS (Angeli's salt)作用时, $580 \mathrm{~nm}$ 处 的苂光有 4 倍的增加, 且该探针有很好的选择性, 能够 用于生物环境中 HNO 的检测. 为了增加探针分子的生 物相容性, Yoon 等 ${ }^{[39]}$ 设计合成了水溶性的探针 21, 该探 针对 HNO 及 $N O$ 都有荧光响应, 且能用于细胞成像. 2016 年邢国文等 ${ }^{[40]}$ 以部花青-咔唑作为苂光基团合成探 针 22, AS 处理以后 $595 \mathrm{~nm}$ 处的苂光明显加强, 能够用 于脂质体中 HNO 的检测.

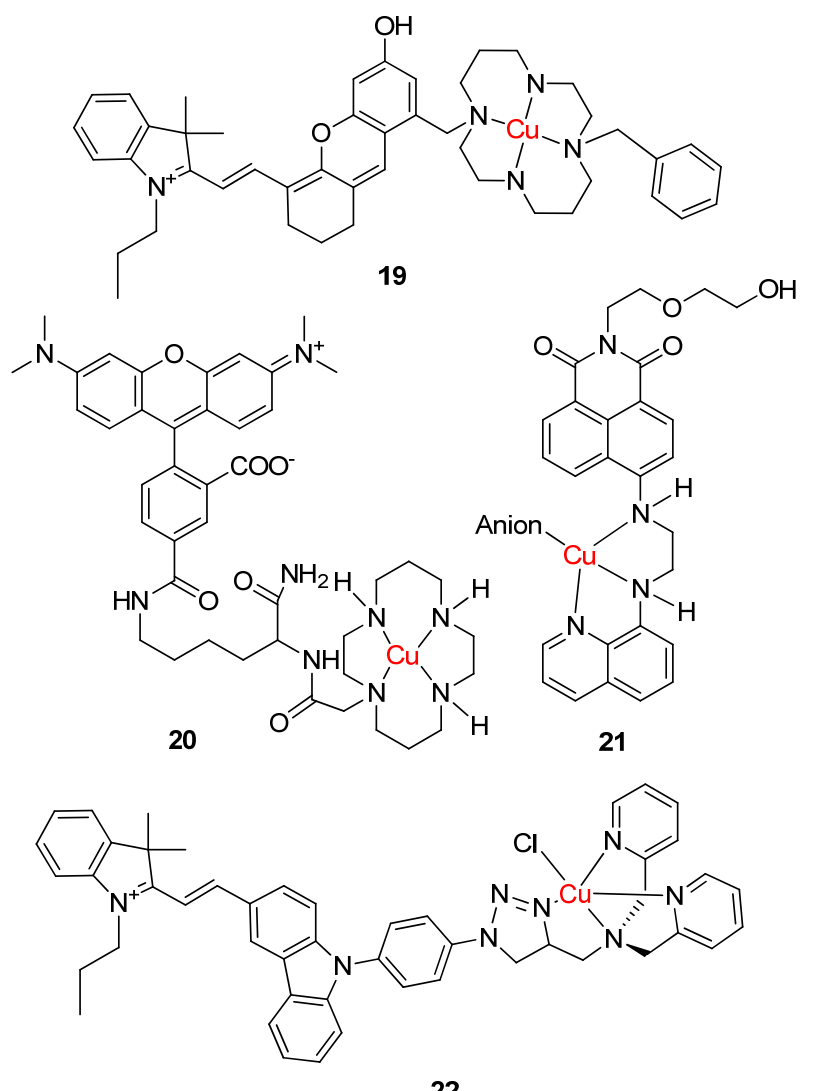

Chan 课题组 ${ }^{[41]}$ 合成了一例以硫醇作为结合位点的 $\mathrm{HNO}$ 探针 23, 该探针响应机理与(二苯基膦基)苯酸盐

类似(Scheme 2). AS 处理后该探针荧光有 16 倍的增强, 硫醇类基团对此均无干扰. 该探针能够用于细胞成像.<smiles>CC(C)(S)C(=O)Oc1c(Cl)cc2c(c1Cl)Oc1cc(O)ccc1C21OCc2ccccc21</smiles>

23<smiles>CC(C)(SNO)C(=O)Oc1c(Cl)cc2c(c1Cl)Oc1cc(O)ccc1C21OCc2ccccc21</smiles><smiles>[O-]c1c(Cl)cc2c(c1Cl)Oc1cc(O)ccc1C21OCc2ccccc21</smiles>

图式 2 探针 23 对 $\mathrm{HNO}$ 的响应机理

Scheme 2 HNO detection mechanism of probe $\mathbf{2 3}$

\section{3 用于 $\mathrm{ONOO}^{-}$检测的荧光探针}

过氧亚硝酸根 $\left(\mathrm{ONOO}^{-}\right)$被认为是生物系统中一种 强氧化剂, 它的存在会导致生物分子氧化并参与各种生 理和病理过程, 这种化学特性使其成为神经退行性疾 病、炎症性疾病、心血管疾病、代谢性疾病、疼痛和癌 症等的致病因子，过氧亚硝酸盐也被证明是生物体免疫 应答和细胞信息传递的重要信号因子. 由于 $\mathrm{ONOO}^{-}$在 细胞内的氧化还原平衡是一个复杂的生物系统氧化还 原过程, 为了阐明 $\mathrm{ONOO}^{-}$发挥其独特生物学作用的机 制, 开发具有高选择性、高灵敏度和高效率的检测方法 显得尤为重要，因此分子荧光探针检测法被生物医学环 境等领域的工作者高度重视 ${ }^{[42,43]}$.

目前设计用于 $\mathrm{ONOO}^{-}$检测的荧光探针主要有以下 几种方式.

第一类是通过 $\mathrm{ONOO}^{-}$对硼酸酯的氧化反应，在与 $\mathrm{ONOO}^{-}$结合以后嗍酸酯基团脱落，探针被氧化成相应 的酚类化合物(Scheme 3), Sikora 课题组 ${ }^{[44]}$ 报道了基于 该原理的荧光素衍生物探针 24 (FBBE), 该探针利用 $\mathrm{ONOO}^{-}$的氧化作用导致嗍酸酯基团破坏， $518 \mathrm{~nm}$ 处荧 光强度增强, 同时, FBBE 探针也用于研究使用阿霉素 蒽环类抗生素多柔比星培育的内皮细胞(Ea.hy926)中的 氧化应激. 王云铭课题组 ${ }^{[45]}$ 在 2017 年又将 4-溴甲基苯 基喼酸频哪醇酯和香豆素相连合成比率型苂光探针 25 . 该探针与 $\mathrm{ONOO}^{-}$反应，苯嗍酸酯基团被氧化，香豆素 苂光团被释放，此时 $390 \mathrm{~nm}$ 处苯硼酸酯苂光强度降低， $450 \mathrm{~nm}$ 处香豆素母核菼光强度增强. 该探针具有毒性 
低、选择性强和灵敏度高等优点, 被成功用于细胞 RAW264.7 和 EAhy926 的内源性外源性 $\mathrm{ONOO}^{-}$的检测. 随后, 朱宝存课题组 ${ }^{[46]}$ 基于 ICT 原理设计并合成了荧光 探针 26. 该探针在与 $\mathrm{ONOO}^{-}$反应后荧光团显色, 颜色 变化肉眼可见. 该探针具有选择性好、灵敏度高、响应 快 $(<5 \mathrm{~s})$ 、检出限低 $\left(0.9\right.$ 和 $\left.17 \mathrm{nmol} \cdot \mathrm{L}^{-1}\right)$ 和细胞毒性低 等优点，可用于活体细胞内源性的苂光成像.

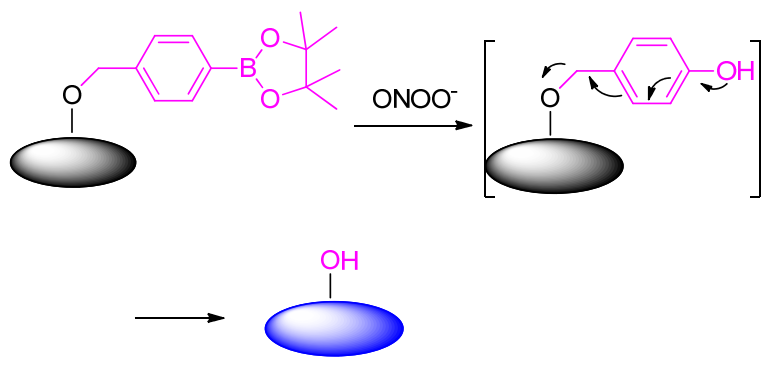

图式 3 硼酸酯被 $\mathrm{ONOO}^{-}$氧化

Scheme 3 Boronate oxidation by $\mathrm{ONOO}$

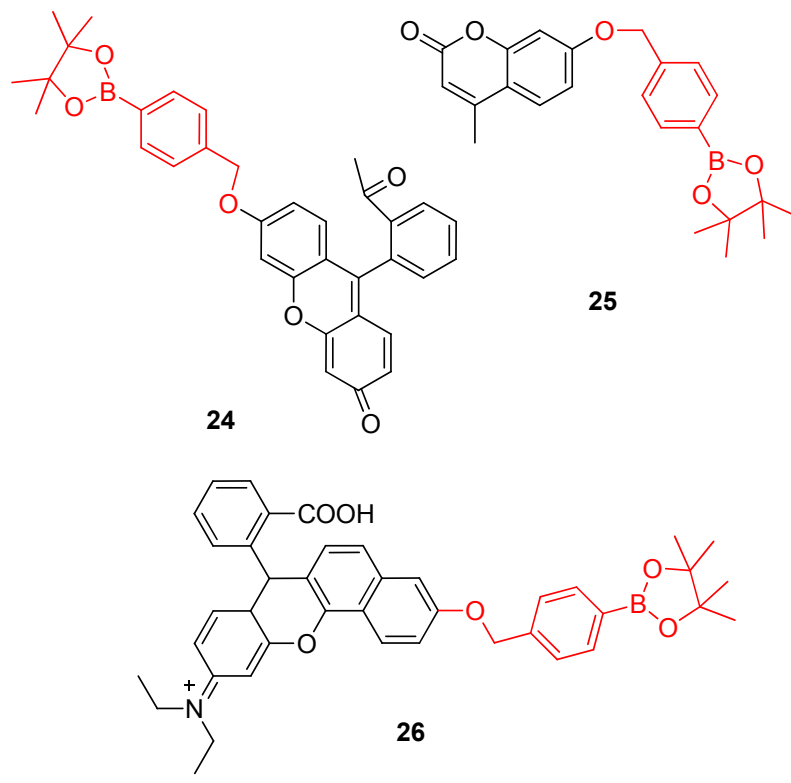

第二种类型是 $\mathrm{ONOO}^{-}$将 $\mathrm{C}=\mathrm{C}$ 和 $\mathrm{C}=\mathrm{N}$ 的双键氧 化断裂. 利用该原理 Yoon 课题组 ${ }^{[47]}$ 设计并合成了由香 豆素-半氰胺连接的红色荧光探针 $\mathbf{2 7}$, 该探针在与不同 浓度 $\mathrm{ONOO}^{-}$反应后, 碳碳双键断裂, 香豆素苂光团释 放, $422 \mathrm{~nm}$ 处苂光强度增强, $568 \mathrm{~nm}$ 处荧光强度减弱, 呈比率型变化, 探针检测限为 $49.7 \mathrm{~nm}$, 具有优异的细 胞膜穿透性, 适合对细胞内源性和外源性 $\mathrm{ONOO}^{-}$进行 测定(Scheme 4). 张向阳课题组 ${ }^{[48]}$ 设计并合成一种基于 分子内质子传递(ESPIT)机理的苯并噻唑衍生物的分子 苂光探针 28, 该探针通过苯并噻唑与肼基吡啶相连引 进 $\mathrm{C}=\mathrm{N}$, 在与过氧硝酸根接触后, $\mathrm{C}=\mathrm{N}$ 键被氧化断裂, $524 \mathrm{~nm}$ 处荧光强度增大 40 倍, 且具有检测限低 $(5.8 \times$ $\left.10^{-8} \mathrm{~mol} \cdot \mathrm{L}^{-1}\right)$ 、响应速度快 $(60 \mathrm{~s}$ 内)和选择性高等优点, 并被成功用于 $\mathrm{HeLa}$ 细胞中的过氧硝酸根成像. 余孝其 课题组 ${ }^{[49]}$ 介绍了一种高水溶性用于内源性 $\mathrm{ONOO}^{-}$检测 的苂光探针 29, 作者采用具有良好光稳定性、大 Stokes 位移和较高量子产率的香豆素支架作为荧光载体, 并通 过引入吡啶基以提高其水溶性. 通过 $\mathrm{C}=\mathrm{C}$ 与可提高水 溶性的吡啶连接，在与过氧亚硝酸盐接触后, $\mathrm{C}=\mathrm{C}$ 被氧 化, $493 \mathrm{~nm}$ 处苂光显现, 具有敏感性高、选择性优异、 反应时间快和细胞毒性低等优点, 已经被成功用于 RAW264.7 中内源性过氧亚硝酸盐的检测.
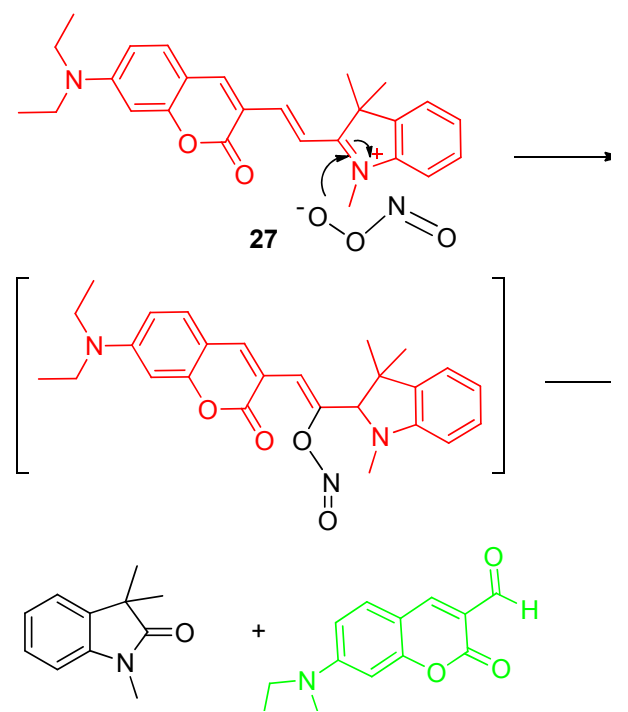

图式 4 探针 27 对 $\mathrm{ONOO}^{-}$的响应机理

Scheme 4 Sensing mechanism of probe 27 for monitoring $\mathrm{ONOO}^{-}$

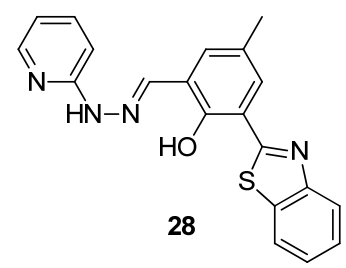<smiles>C[n+]1ccc(/C=C/c2cc3cc4c5c(c3oc2=O)CCCN5CCC4)cc1F</smiles>

第三类是利用硒、碲的氧化来实现探针荧光的变化. 2017 年, 孙春龙课题组 ${ }^{[50]}$ 报道了一个用于线粒体靶向 的荧光探针 30 用于检测细胞和体内的 $\mathrm{ONOO}^{-}$. 以往研 究表明, 细胞抗氧化防御系统对细胞中 $\mathrm{ONOO}^{-}$的浓度 具有调控作用, 硒在谷胱甘肽过氧化物酶的活性位点中 起重要作用. 该探针则是模拟硒酶对 $\mathrm{ONOO}^{-}$和谷胱甘 肽的催化反应，具有高灵敏度、高选择性、背景干扰小 和细胞毒性低等特点, 被成功用于 HeLa 细胞和 RAW264.7 细胞检测 $\mathrm{ONOO}^{-}$并成像. 碲酶模拟物的活 性比硒酶模拟物更高, 且因为碲能与邻位氮原子形成可 逆的环化反应，抑制了 $\mathrm{ONOO}^{-}$对碲酶模拟物的过度氧 化. 2013 年, 韩克利课题组 ${ }^{[51]}$ 报道了一个基于花青类衍 
生物的近红外苂光探针 31 , 用于检测细胞和体内的 $\mathrm{ONOO}^{-}$(图 3). 该探针成功在生理条件下监测 $\mathrm{ONOO}^{-}$ 氧化/谷胱甘肽还原过程. 探针具有较高的选择性, 敏感 性和线粒体靶向性, 检测限低至 $9.17 \times 10^{-7} \mathrm{~mol} \cdot \mathrm{L}^{-1}$, 探 针在与 $\mathrm{ONOO}^{-}$接触后 $\mathrm{Te}$ 被氧化, $820 \mathrm{~nm}$ 处苂光强度达 到峰值, 可用于观察 $\mathrm{ONOO}^{-}$爆发期间氧化还原周期的 变化及抗氧化细胞和动物的谷胱甘肽 $(\mathrm{GSH})$ 修复, 并成 功应用于 RAW 264.7 细胞和小鼠腹腔中的 $\mathrm{ONOO}^{-}$检测.
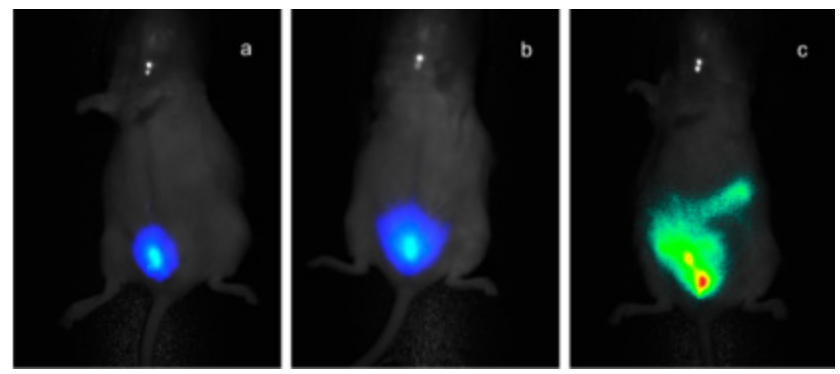

图 3 探针 31 用于小鼠体内检测 $\mathrm{ONOO}^{-}$成像

Figure 3 Fluorescence imaging of the mice treated with probe 31 to detect $\mathrm{ONOO}^{-}$

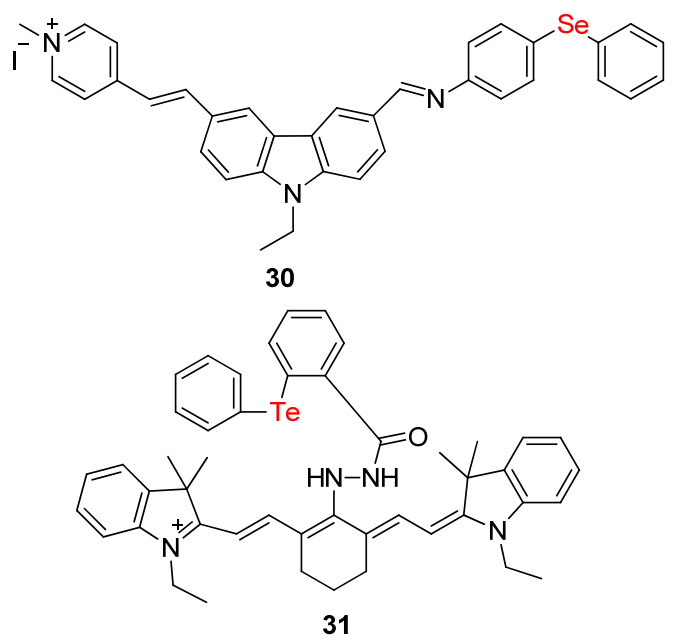

除了上面硼酸酯、 $\mathrm{C}=\mathrm{N} 、 \mathrm{C}=\mathrm{C}$ 作为响应基团和模 拟硒酶对 $\mathrm{ONOO}^{-}$和谷胱甘肽的催化反应外，还发展了 一系列具有其他响应基团的苂光探针.

龚兵和卢忠林课题组 ${ }^{[52]}$ 报道了一种基于芳构化 9,10-二氢唤啶衍生物显示荧光用于 $\mathrm{ONOO}^{-}$检测的探针 32. 在 $\mathrm{ONOO}^{-}$检测过程中氧化苂光探针使其芳构化, 形成大 $\pi$ 面, 荧光由无到有, 最大值为 $496 \mathrm{~nm}$ (Eq. 10). 该探针具有选择性强和响应快速等优点, 在探针溶液中 加入少于 1 equiv. 的 $\mathrm{ONOO}^{-}$导致超过 100 倍的苂光增强, 并成功实现 RAW 264.7 细胞中的 $\mathrm{ONOO}^{-}$检测.

袁林课题组 ${ }^{[53]}$ 报道了一个基于能量转移(FRET)机 制的双光子比率苂光 $\mathrm{ONOO}^{-}$探针 33, 该探针与 $\mathrm{ONOO}^{-}$ 反应使得电子转移到母核上苂光强度增强( Eq. 11). 该 双光子比率荧光探针通过对两个发射带(473 和 $651 \mathrm{~nm}$ )<smiles>O=C(O)C1=CC=CC2C1Nc1ccccc1C2c1ccccc1</smiles>

标定，消除了探针浓度、探测环境和激发强度等因素所 造成的不利影响，使得检测速度快(20 s 以内)且灵敏度 高(检出限 $11.30 \mathrm{nmol} \cdot \mathrm{L}^{-1}$ ), 对 $\mathrm{ONOO}^{-}$选择性好, 并应 用于 HepG 2/RAW 264.7 细胞内源性 $\mathrm{ONOO}^{-}$的比值检 测.<smiles></smiles><smiles>CCN(CC)C1=CC(O)C(/C(=C/C(=O)O)c2ccccc2C(=O)O)C=C1</smiles><smiles>CCN(CC)c1ccc2cc(C(=O)N3CCN(c4ccc(O)cc4)CC3)c(=O)oc2c1</smiles>

王云铭课题组 ${ }^{[54]}$ 在 2013 年报道了一种以丹磺酰氯 为苂光团, 邻苯二胺作为响应基团的 $N$ - $(2$-氨基苯 基)-5-(二甲基氨基)-1-菜磺酰胺(Ds-DAB)分子苂光探针 34. $\mathrm{ONOO}^{-}$首先经过亲核亚硝化反应形成亚硝胺，然后 质子化水解，最终产生具有苂光性质的丹酰酸以及苯并 三唑(Eq. 12). 向 Ds-DAB 水溶液中加入 $\mathrm{ONOO}^{-}$会导致 $505 \mathrm{~nm}$ 处苂光强度明显增强，该探针具有灵敏度高(检 测限为 $\left.52.4 \mathrm{nmol} \cdot \mathrm{L}^{-1}\right)$ 、响应快 $(20 \mathrm{~s})$ 和选择性高等优点, 成功实现对小鼠巨噬细胞内源性过氧亚硝酸盐的检测 及苂光成像，具有定量检测 $\mathrm{ONOO}^{-}$的潜力.

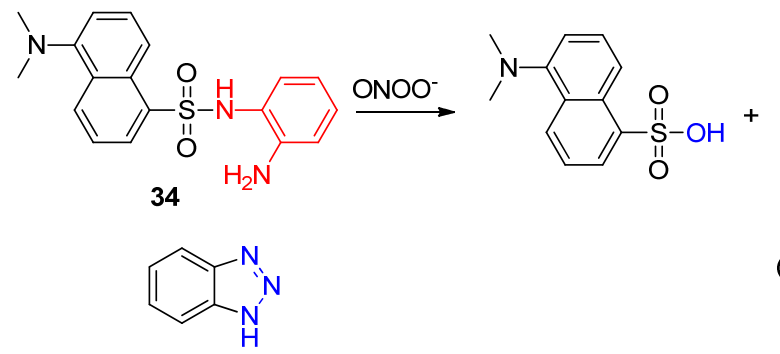


$\mathrm{ONOO}^{-}$的水溶性荧光探针 35. 其中 $D$-果糖可以阻止探 针被其余 RNS 或者 ROS 破坏, 也增强了探针苂光强度, 选择性提高. 该探针在与 $\mathrm{ONOO}^{-}$反应后, 含共价电子 对的叔胺 PET 过程被解锁(Scheme 5), 荧光强度减弱, 并成功用于细胞 RAW264.7 和 HeLa 成像实验, 检测内 源性和外源性过氧亚硝酸根, 并完美成像. 马会民课题 组 ${ }^{[56]}$ 设计并合成了探针 36, 罗丹明与苯肼反应合成的 带有内酰胺环结构的探针分子, 由于该内酰胺环的存 在，化合物自身没有苂光，当与 $\mathrm{ONOO}^{-}$反应后内酰胺 环打开, 罗丹明处的荧光恢复, 利用该关-开机理实现 了对 $\mathrm{ONOO}^{-}$的检测, 在探针设计中, 作者还引入了三 苯基膦作为线粒体靶向基团，从而实现了对线粒体内 $\mathrm{ONOO}^{-}$的检测. 该探针具有选择性好、灵敏度高、检测 限低 $\left(53 \mathrm{nmol} \cdot \mathrm{L}^{-1}\right)$ 和细胞毒性低等优点, 成功用于活体 细胞内源性的苂光成像. 同样利用罗丹明内酰胺环的
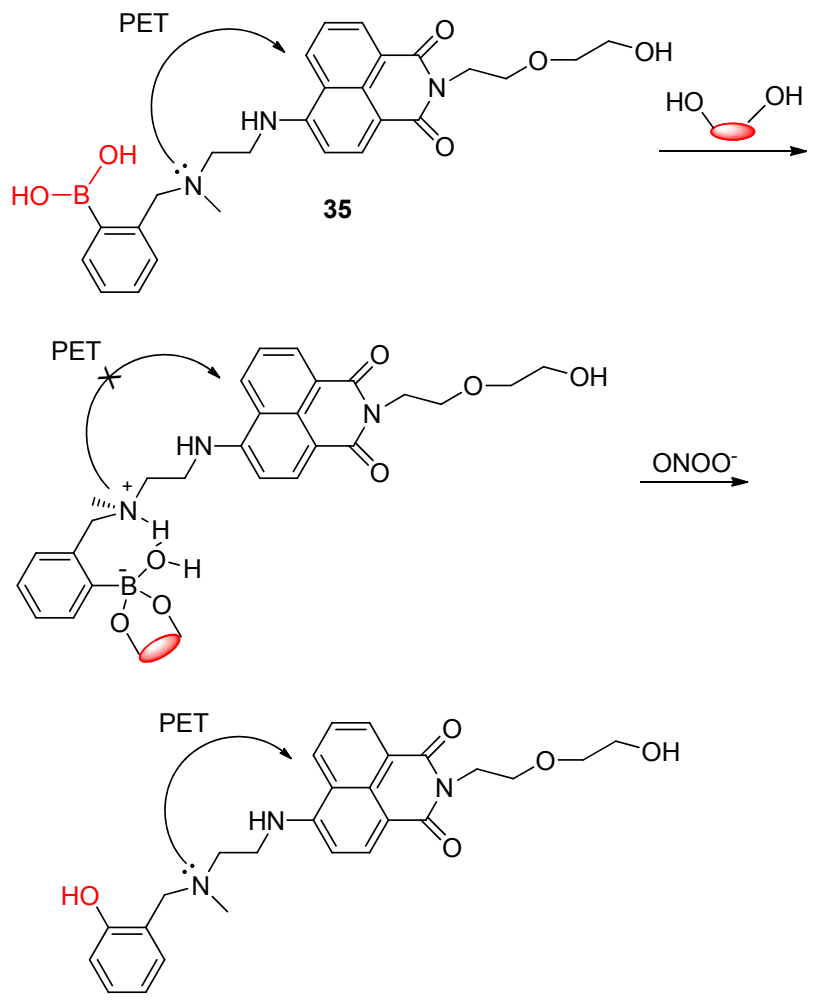

图式 5 探针 35 对 $\mathrm{ONOO}^{-}$的响应机理 Scheme 5 Response mechanism of probe 35 to ONOO

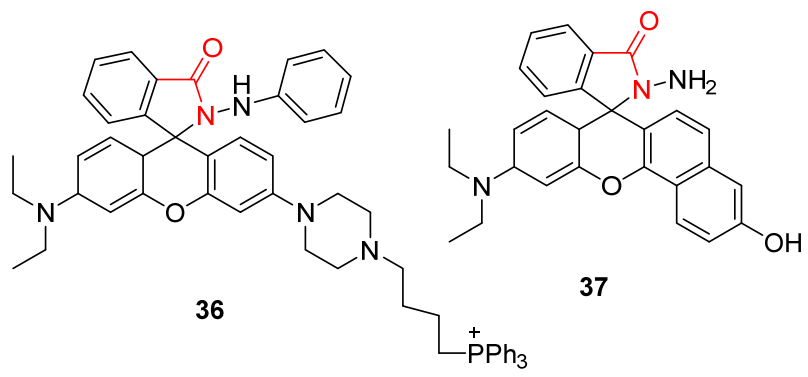

关-开机理, 朱宝存课题组 ${ }^{[57]}$ 设计了探针 37 , 该探针响 应快 $(<5 \mathrm{~s})$ 且检出限更低 $\left(0.9\right.$ 和 $\left.17 \mathrm{nmol} \cdot \mathrm{L}^{-1}\right)$, 也被成 功用于活体细胞内源性的苂光成像.

\section{4 用于 $\mathrm{NO}_{2}^{-}$检测的荧光探针}

亚硝酸根离子 $\left(\mathrm{NO}_{2}^{-}\right)$是一类常见于生产生活中的 无机盐类. 一方面, $\mathrm{NO}_{2}^{-}$在胃中可以与胃中蛋白质作 用生成致癌物质亚硝胺; 另一方面, $\mathrm{NO}_{2}^{-}$对血液循环 和低氧性 NO 的动态平衡起到调节作用, 并被作为血管 扩张剂用于心脏疾病的治疗, $\mathrm{NO}_{2}^{-}$在血液中可将低铁 血红蛋白转化成高铁血红蛋白, 氧气运输受阻造成组织 缺氧. 因此, 对于 $\mathrm{NO}_{2}^{-}$的检测具有重要意义 ${ }^{[58]}$.

基于 BODIPY 苂光团, 2013 年 Ramaiah 课题组 ${ }^{[59]}$ 设计并合成一个用于日常水源中 $\mathrm{NO}_{2}^{-}$检测的荧光探针 38. 探针在 BODIPY 的 3,5-位引入苯胺作为响应基团, 与 $\mathrm{NO}_{2}^{-}$反应发生重氮化反应, 氨基转化为羟基, 波长 发生红移, 肉眼可见溶液颜色由蓝变绿, 探针在对水源 $\mathrm{NO}_{2}^{-}$检测过程中不受其余存在阴阳离子的干扰，选择 性高, 检测限为 $2 \times 10^{-5} \mathrm{~mol} \cdot \mathrm{L}^{-1}$. 与上述反应原理相同, 2018 年, 张卫娟课题组 ${ }^{[60]}$ 报道了一个以 BODIPY 为荧 光团, 邻苯二胺作为响应基团在酸性条件下检测 $\mathrm{NO}_{2}^{-}$ 的苂光探针 39. 在与 $\mathrm{NO}_{2}^{-}$重氮化反应后, $532 \mathrm{~nm}$ 处苂 光强度增强, 颜色由蓝变成黄绿色, 肉眼可见, 探针具 有高选择性和高灵敏度等优点，被成功应用于 HepG2 检测 $\mathrm{NO}_{2}^{-}$(Scheme 6).

\section{5 用于 $\mathrm{NO}_{2}$ 检测的荧光探针}

$\mathrm{NO}_{2}$ 是一种可以在空气中稳定存在的红棕色气体, 不仅污染环境, 对人体芳香族氨基酸也具有强氧化性, 引发氨基酸发生硝化反应, 同时亲脂性强, 可引起脂质 的自氧化反应. 因此, 对于 $\mathrm{NO}_{2}$ 的检测具有重要意义. 迄今为止，已报道的对于 $\mathrm{NO}_{2}$ 检测的探针较少. 2013 年, 黄德建课题组 ${ }^{[61]}$ 介绍了探针 40, 该探针以磺酰罗丹明 B 作为苂光基团, 通过二硫代氨基甲酸镍对磺酰罗丹明 $\mathrm{B}$ 的 PET 作用导致苂光淬灭 (Scheme 7). 当 $\mathrm{NO}_{2}$ 存在时, 二硫代氨基甲酸镍与之发生络合反应生成新络合物和 自由基, PET 过程被阻止, 苂光团荧光开启, $590 \mathrm{~nm}$ 处苂 光强度增强. 与对位异构体 40B 相比, 邻位异构体 40A 中苂光团与 $\mathrm{Ni}^{2+}$ 之间的距离更短(分别为 0.74 和 0.94 $\mathrm{nm}$ ), 而 PET 作用的强度与距离成反比, 因此探针 40A 中 PET 作用更加敏感, 具有更高的选择性和灵敏度, 并 成功实现了 RAW 264.7 细胞中外源性 $\mathrm{NO}_{2}$ 的检测.

2017 年, 孙杰课题组 ${ }^{[62]}$ 报道了两个高选择性的苂 光探针 41A 和 41B. 两个苂光探针均以香豆素作为苂光 团母核，响应基团都是肜基团， $41 \mathrm{~A}$ 探针是通过与 $\mathrm{NO}_{2}$ 反应后肜基团被氧化，荧光团开启, $425 \mathrm{~nm}$ 处荧光强度 

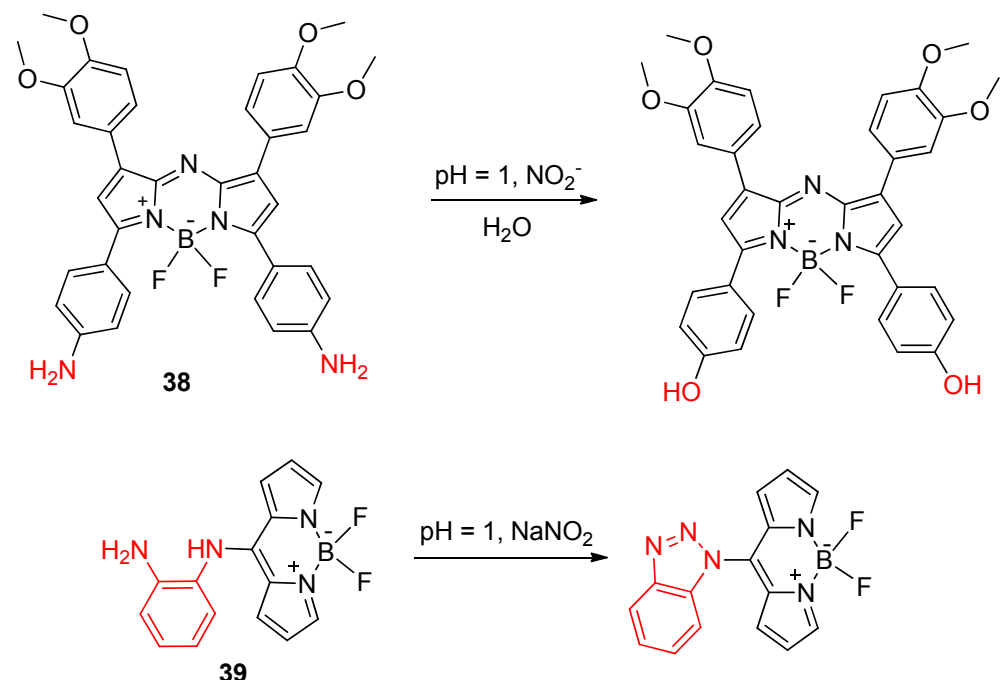

图式 6 探针 38 和 39 对 $\mathrm{NO}_{2}^{-}$的响应机理

Scheme 6 Response mechanism of probes 38 and 39 to $\mathrm{NO}_{2}^{-}$

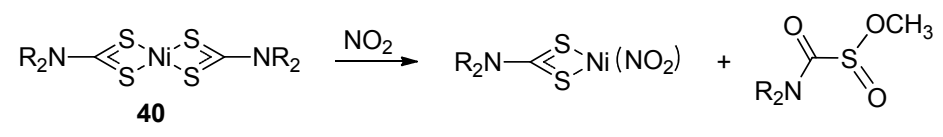<smiles></smiles>

$40 \mathrm{~A}$<smiles>CCN(CC)c1ccc(-c2c3ccc(N(CC)CC)cc3cc3cc(N(CC)CC)ccc23)c([R5](=O)(=O)O)c1</smiles>

$40 B$

图式 7 探针 40 对 $\mathrm{NO}_{2}$ 的响应机理

Scheme 7 Response mechanism of probe $\mathbf{4 0}$ to $\mathrm{NO}_{2}$

增强; 41B 则正好相反, 由于扭曲的分子内电荷转移机 制而表现出独特的关闭响应，苂光猝灭率约为 $98 \%$ (Scheme 8). 通过实验证明, 41B 探针的响应效果较好, 选择性强, 灵敏度高, 独特的荧光猝灭策略可用于构建<smiles>CN(C)c1ccc2ccc(=O)oc2c1C=NO</smiles>

41A<smiles>CN(C)c1ccc2cc(/C=N/O)c(=O)oc2c1</smiles>
41B

图式 8 探针 41A 和 $41 B$ 对 $\mathrm{NO}_{2}$ 的响应机理 Scheme 8 Response mechanism of probes $41 \mathrm{~A}$ and $41 \mathrm{~B}$ to $\mathrm{NO}_{2}$
新的传感器系统和荧光放大聚合物, 用于 $\mathrm{NO}_{2}$ 和硝胺的 超痕量检测.

\section{3 用于活性氧检测的分子荧光探针}

\section{1 用于次氯酸检测的荧光探针}

日常生活中, 次氯酸及次氯酸盐可以说是最强的氧 化剂之一. $\mathrm{HClO}$ 作为一种常见的杀菌剂, 被人们广泛使 用, 例如公共供水消毒剂、杀菌剂及家用漂白剂等. 活 性氧现在被普遍认为是病理生理中重要的一个存在环 节, 其中, 生物体内源性次氯酸主要产生于白细胞, 在 $\mathrm{H}_{2} \mathrm{O}_{2}$ 和髓过氧化物酶共同作用下与 $\mathrm{Cl}^{-}$结合, 生成具有 强氧化作用的次氯酸根. 生物系统的 $\mathrm{HClO}$ 正常水平波 动范围较窄，水平异常都将导致各种疾病的产生，例如 心脑血管疾病、动脉秙样化、神经性疾病和癌症等. 针 对次氯酸找到一种高灵敏度、易于操作、价格低廉的检 测方法尤为重要, 因此, 荧光探针被列为主要研究对象, 
具有细胞动力学可视化、生物分子高分辨定位等优点, 被环境生物医学等领域高度重视 ${ }^{[63,64]}$. 目前检测次氯酸 的荧光探针响应基团反应类型主要有以下几种: 氧化 $\mathrm{C}=\mathrm{N} 、 \mathrm{C}=\mathrm{C}$ 键使之断裂, 氧化 $\mathrm{C}=\mathrm{N} 、 \mathrm{C}=\mathrm{C}$ 键生成 $\mathrm{CN}$ 、三元环等, 罗丹明类螺内酰胺环开环反应, 氧化含 氧族化合物(硫、硒和碲元素), 氧化酰肼反应和其它类 型氧化反应.

第一种类型, 在温和的条件下, 次氯酸可以选择性 的氧化 $\mathrm{C}=\mathrm{N} 、 \mathrm{C}=\mathrm{C}$ 键并使其断裂, 阻断荧光团向连接 基团的作用, 进而促进荧光母体信号释放. 吴淑褓课题 组 ${ }^{[65]}$ 介绍了一个基于 BODIPY 衍生物的 “打开型” 苂光 探针 42. 探针引进 $\mathrm{C}=\mathrm{N}$ 双键对荧光团淬灭, 当与 $\mathrm{ClO}^{-}$ 接触被氧化后, 苂光团在 $508 \mathrm{~nm}$ 处显色(Eq. 13). 该探 针具有选择性高和检测限低等优点, 在共聚焦荧光显微 镜下 RAW 264.7 细胞的成像结果表明, 新的探针可作为 检测活细胞中 $\mathrm{ClO}^{-}$的有效荧光探针. 基于同一机理, 姜 世梅课题组 ${ }^{[6]}$ 设计并合成萠类荧光探针 43. 该类探针 以萠作为荧光团, 通过 $\mathrm{C}=\mathrm{N}$ 连接给电子的苯肼基团, 由于 PET 作用其给电子基团对荧光团起到一个淬灭的 效应, 在与 $\mathrm{ClO}^{-}$反应后, $\mathrm{C}=\mathrm{N}$ 被氧化断裂(Eq. 14), 荧 光团苂光显著增强 42.6 倍, 并成功应用于 HeLa 细胞成 像(图 4). 吴水珠和曾钫课题组 ${ }^{[67]}$ 也基于此机理做了相 关工作.
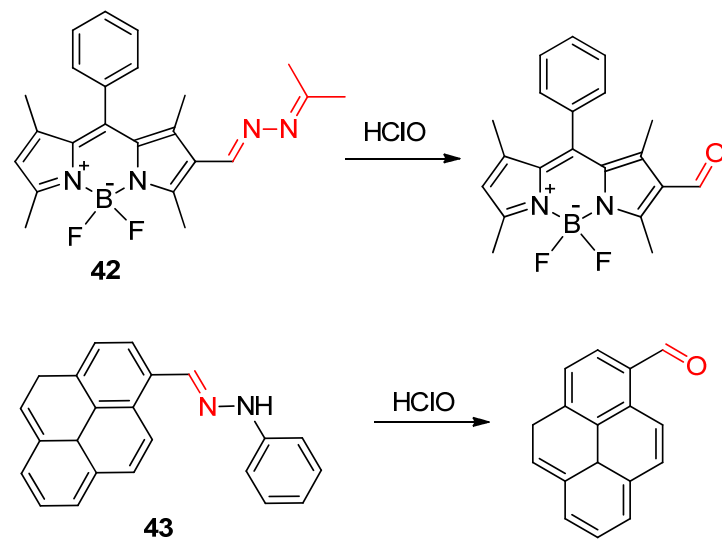

陈小强和王芳课题组 ${ }^{[68,69]}$ 在 2017 年设计了一种用 于线粒体中 $\mathrm{ClO}^{-}$检测的比率型苂光探针 $\mathbf{4 4}$ (Eq. 15). 该 探针以吡啶为线粒体识别基团, 苯并噻唑连接苯环作为 荧光团. 由于其优异的水溶性、选择性、特异性、快速 响应 $(30 \mathrm{~s}$ 内 $)$ 和低检测限 $\left(0.18 \mathrm{mmol} \cdot \mathrm{L}^{-1}\right)$ 等优点, 在 Hela 细胞中成功应用并用于 $\mathrm{ClO}^{-}$的定量检测. 该课题 组于 2018 年进一步合成了探针 $\mathbf{4 5}$, 当探针与 $\mathrm{ClO}^{-}$接触 后, $\mathrm{C}=\mathrm{C}$ 断裂(Eq. 16), $530 \mathrm{~nm}$ 处荧光增强且与 $\mathrm{ClO}^{-}$的 浓度 $\left(0 \sim 50 \mu \mathrm{mol} \cdot \mathrm{L}^{-1}\right)$ 呈线性关系. 同样利用 $\mathrm{C}=\mathrm{C}$ 被氧 化, 赵宝祥课题组 ${ }^{[70]}$ 设计了一例基于 FRET 机理并用于

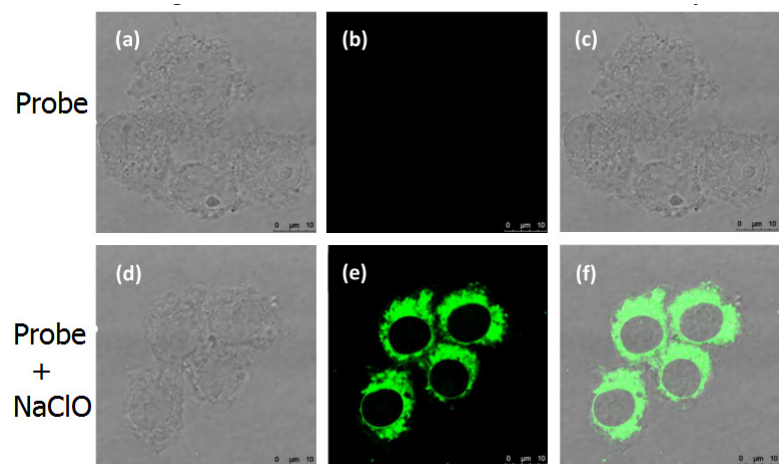

图 4 探针 43 与次氯酸反应的细胞成像

Figure 4 Cellular imaging of probe 43 reacting with hypochlorous acid
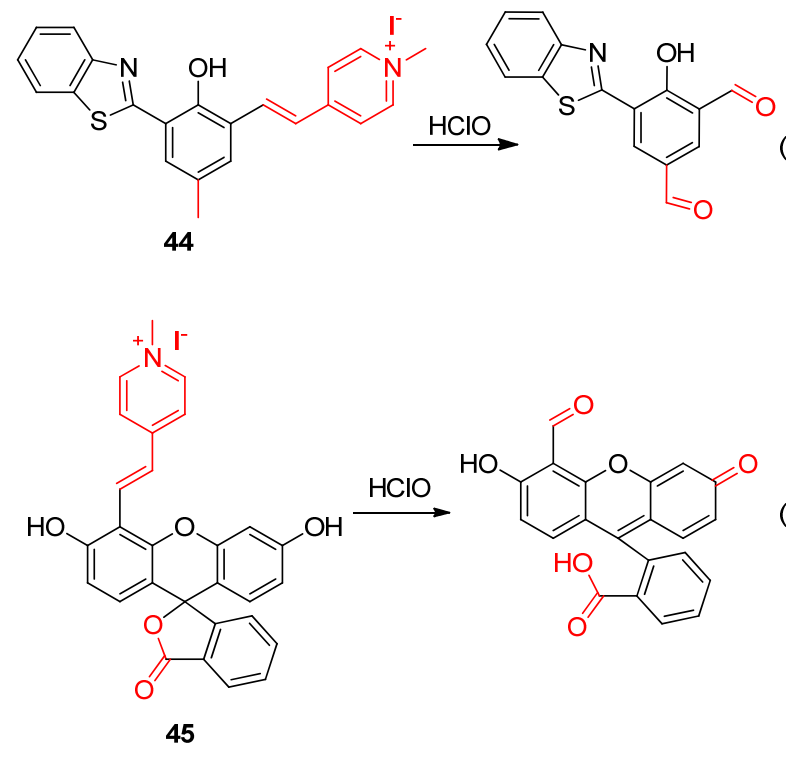

近红外区的探针 46 (Eq. 17), 探针与 $\mathrm{ClO}^{-}$接触后, $25 \mathrm{~s}$ 内 可显示出清晰的响应，苂光颜色由红色向亮黄色明显变 化, 肉眼可识别, 检测限低至 $0.19 \mu \mathrm{mol} \cdot \mathrm{L}^{-1}$. 苂光发射 出现在近红外区(NIR), 在细胞成像中对 $\mathrm{ClO}^{-}$可灵敏识 别并具有选择性. 在这一方面该课题组 ${ }^{[71]}$ 还做过相关 工作．同样应用于近红外区域，曾林涛课题组 ${ }^{[72]}$ 合成了 探针 47 (Eq. 18), 该探针由 7-二乙基氨基香豆素与苯并 $[e]$ 吲哚组成, 通过 $\mathrm{C}=\mathrm{C}$ 连接, 当 $\mathrm{C}=\mathrm{C}$ 键被 $\mathrm{ClO}^{-}$破坏 后, 探针显示对 $\mathrm{ClO}^{-}$的比色荧光和比值荧光双重响应, $658 \mathrm{~nm}$ 处苂光强度降低, $475 \mathrm{~nm}$ 处增强(图 5). 该探针 具有选择性高、响应速度快(90 s) 和较低的检测限(33 $\mathrm{nmol} \cdot \mathrm{L}^{-1}$ ) 等优点，并被成功应用于 Hela 细胞的 $\mathrm{ClO}^{-}$检 测和细胞成像, 且可以实现活细胞内 $\mathrm{ClO}^{-}$的定量检测.

仍然是基于双键被氧化的特点, 还有 $\mathrm{C}=\mathrm{N}$ 双键氧 化成- $\mathrm{CN}$ 基、双键成三元环等其他反应类型. 王传明课 题组 ${ }^{[73]}$ 介绍了一个用于内源性 $\mathrm{HClO}$ 检测的 “打开型” 双光子荧光探针 48. 该探针以 1,8 -䒬酰亚胺作为荧光 

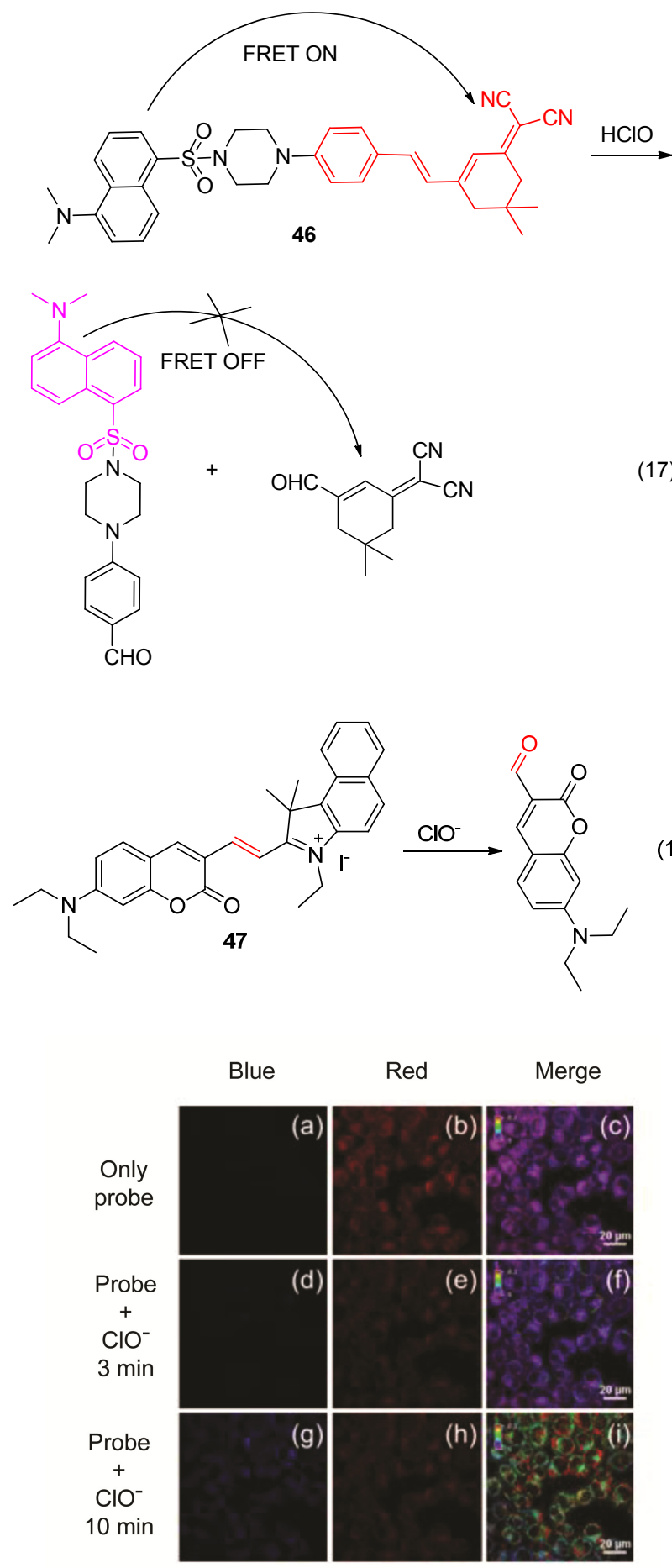

图 5 探针 47 与次氯酸反应的细胞成像

Figure 5 Cellular imaging of probe 47 reacting with hypochlorous acid

才, $3^{\prime}$ 位引入苂光淬灭基团, 当与 $\mathrm{HClO}$ 作用时, $\mathrm{C}=\mathrm{N}$ 双 键被氧化成 $\mathrm{CN}$ 基(Eq. 19), 苂光恢复. 该探针保留了羟 基和化合物的光学特性, 同时大大提高了产物的水溶 性，具有双光子吸收、抗漂白、细胞吸收效率高、无细 胞毒性等多种优点, 双光子激发下 $(800 \mathrm{~nm})$, 穿透深度 达 $150 \mu \mathrm{m}$, 并在细胞 RAW 264.7 和小鼠肝脏组织进行
试验成功, 可以作为一种成像工具来揭示 $\mathrm{HClO}$ 在广泛 的病理过程中的作用.

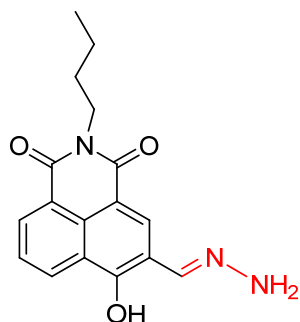

48
$\stackrel{\mathrm{HClO}}{\longrightarrow}$

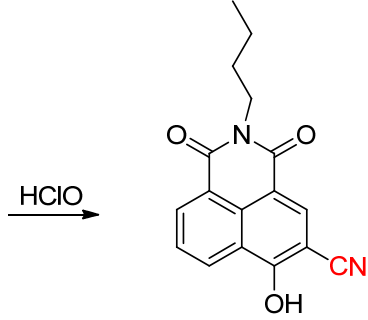

(19)
王素华课题组 ${ }^{[74]}$ 亦通过氧化 $\mathrm{C}=\mathrm{C}$ 双键进行苂光探 针的设计，合成了一例处于近红外区域的荧光探针 49, 该探针与 $\mathrm{HClO}$ 接触后，母核碳碳双键被氧化形成三元 环(Eq. 20), $774 \mathrm{~nm}$ 处苂光淬灭. 该探针具有低检测限 $\left(0.13 \sim 0.70 \mu \mathrm{mol} \cdot \mathrm{L}^{-1}\right)$ 的特点, 在生理 $\mathrm{pH}$ 条件下稳定, 并成功在活 A549 细胞中成像. 林伟英课题组 ${ }^{[75]}$ 也基于 该机理合成了一种具有大位移并用于 $\mathrm{ClO}^{-}$检测的比率 型苂光探针 50. 除了双键被氧化成三元环外，同时该探 针中带正电的 $\alpha, \beta$-不饱和羰基在与 $\mathrm{ClO}^{-}$反应后断裂(Eq. 21 ), 探针本身在 $662 \mathrm{~nm}$ 处显示近红外(NIR)苂光，与 $\mathrm{ClO}^{-}$反应时可以在 $456 \mathrm{~nm}$ 处显示强蓝色菼光，具有灵 敏度高、选择性好、生理 $\mathrm{pH}$ 值高和细胞毒性低等优点. HeLa 细胞的生物成像实验中表明，该探针可成功地用 于 $\mathrm{ClO}^{-}$在活体细胞中的比值成像.

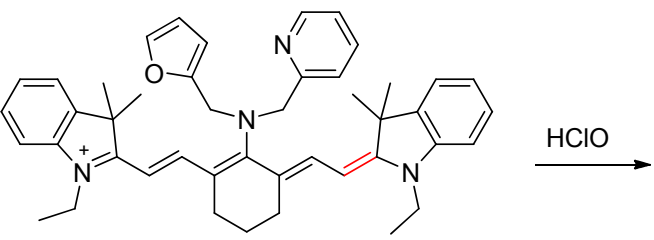

49
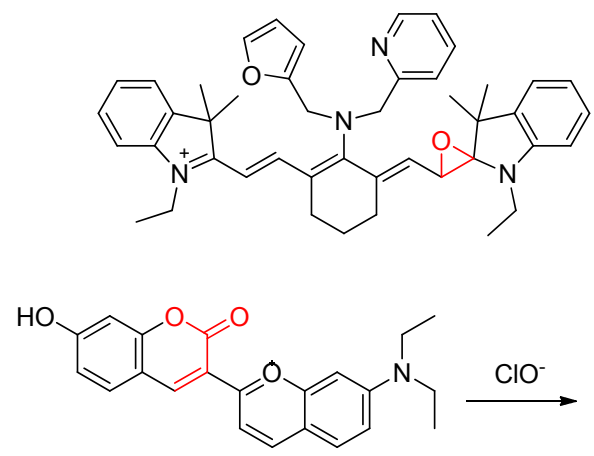

50<smiles>CCN(CC)c1ccc(C2OC2C(=O)c2cc3ccc(O)cc3oc2=O)c(O)c1</smiles> 
彭孝军课题组 ${ }^{[76]}$ 介绍了一种基于 BODIPY 衍生物 的 “增强型 PET” 苂光探针 51. 该探针中位的吡咯基团 对 BODIPY 苂光团具有 “增强的 PET” 效应，与次氯酸 根反应后, 吡咯上的双键被氧化成酮(Eq. 22), PET 效应 被阻止, $505 \mathrm{~nm}$ 处荧光强度增强且与 $\mathrm{ClO}^{-}$的浓度 $(0 \sim 10$ $\left.\mathrm{nmol} \cdot \mathrm{L}^{-1}\right)$ 成线性关系. 该探针具有灵敏度高 $(1 \mathrm{~s}$ 内 $)$ 和 选择性强等优点, 检测限低至 $0.56 \mathrm{nmol} \cdot \mathrm{L}^{-1}$, 已被成功 应用于细胞 MCF-7 和人体肿瘤细胞中 $\mathrm{ClO}^{-}$的检测.

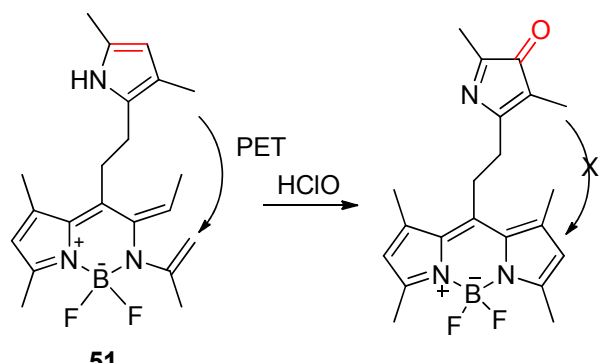

第二种类型是基于罗丹明类螺内酰胺环开环反应. Yoon 课题组 ${ }^{[77]}$ 报道了一个用于 $\mathrm{ClO}^{-}$检测及诱导微生物 中 $\mathrm{ClO}^{-}$合成的苂光探针 52. 该探针选用硣酸酯和硫代 内酯作为苂光团, 使探针具有较低的苂光产率, 并且这 种双控制光能团有效的提高了探针的选择性, 其与 $\mathrm{ClO}^{-}$反应后, 硫代内酯环开启生成一种高苂光强度的 苂光素化合物(Eq. 23), 颜色从无色到绿色, 苂光发射峰 为 $523 \mathrm{~nm}$, 苂光强度与 $\mathrm{ClO}^{-}$浓度成线性关系 $(0 \sim 1.0$ $\mu \mathrm{mol} \cdot \mathrm{L}^{-1}$ ), 在生理 $\mathrm{pH}$ 下稳定性良好, 对于体内成像检 测具有重要意义. 同样利用罗丹明硫代内脂环的关一开 机理, 马会民和史文课题组 ${ }^{[78]}$ 设计并合成了探针 53, 用 于检测巨噬细胞中的 $\mathrm{ClO}^{-}$(Eq. 24). 探针引入了三苯 基膦作为线粒体靶向基团，因此该探针具有良好的线粒 体靶向性，值得注意的是，以非吞噬细胞和抑制剂作为 对照, 该探针首次发现了在细菌感染过程中巨噬细胞内 线粒体 $\mathrm{HClO}$ 的出现. 该探针还具有反应速度快、选择 性好、灵敏度高及检测限低 $\left(9 \mathrm{nmol} \cdot \mathrm{L}^{-1}\right)$ 的优点, 可以用 于次氯酸的追踪工作. 在此之前作者还做过大量相关工 作 ${ }^{[79,80]}$.<smiles>CC(C)(C)C1(C)OB(c2ccc3c(c2)Oc2cc(Oc4ccc5c(-c6ccccc6C(=O)[O-])c6ccc(=O)cc-6oc5c4)ccc2C32SC(=O)c3ccccc32)OC1(C)C</smiles>

利用次氯酸对罗丹明内酰胺环的氧化作用, 张桢课 题组 ${ }^{[81,82]}$ 于 2015、2016 年分别设计了探针 54 和 55. 两 个化合物均以罗丹明 $6 \mathrm{G}$ 为苂光团, 与 $\mathrm{ClO}^{-}$接触后, 内

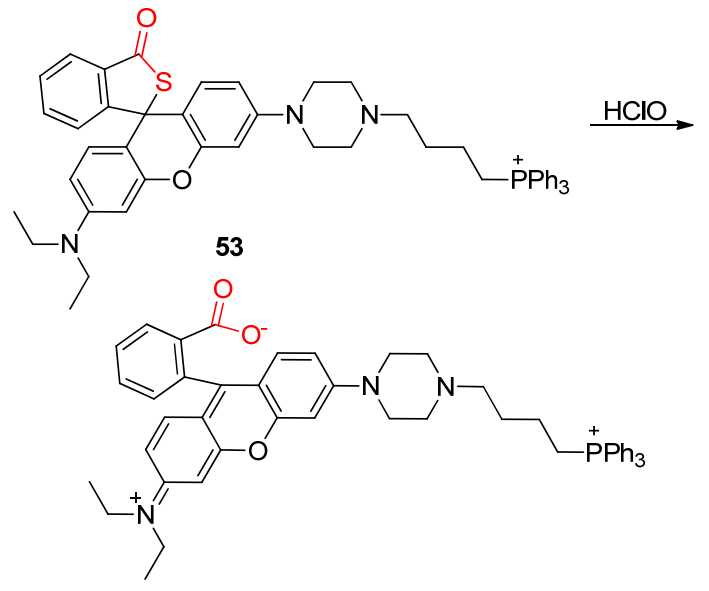

酰胺环打开, $550 \mathrm{~nm}$ 处苂光逐渐增强. 前者具有高灵敏 度、低细胞毒性和良好的细胞膜渗透性，被广泛用于细 胞中 $\mathrm{ClO}^{-}$的成像检测; 后者被成功地用于监测自来水 中微量的 $\mathrm{HClO}$, 并对活细胞 A549 和 RAW264.7 的外源 性和内源性 $\mathrm{HClO}$ 成像, 具有响应速度快、检出限低及 $\mathrm{pH}$ 检测范围较宽等优点, 可以促进更多 $\mathrm{HClO}$ 相关的化 学和生物学研究. Wong 课题组 ${ }^{[83]}$ 报道了一种母核具有 罗丹明和苂光素优点的罗多尔衍生物苂光探针 56. 该 苂光探针通过引进修饰基团异硫氰酸苯酯基，在 $\mathrm{HClO}$ 存在下内酰胺开环再发生环化反应，生成罗丹明-噁二 唑(Eq. 25), 新的苂光发射峰在 $612 \mathrm{~nm}$, 具有高选择性 和高灵敏度，在生理 $\mathrm{pH}$ 下功能优异，并成功应用于 $\mathrm{HeLa}$ 细胞苂光成像.<smiles>CCNc1cc2c(cc1C)C1(c3cc(NC(=O)c4cccc5ccccc45)c(C)cc3O2)c2cc(C)c(NCC)cc2C(=O)N1C(=O)c1ccccc1</smiles><smiles>CCNc1cc2c(cc1C)C1(c3cc(C)c(NCC)cc3O2)c2ccccc2C(=O)N1NC(=O)c1ccccn1</smiles>

55<smiles>CCN(CC)c1ccc2c(c1)Oc1c(cc3c(-c4ccccc4)c4ccc(=O)c(C)c-4oc3c1C)C21c2ccccc2C(=O)N1NC(=S)Nc1ccccc1</smiles><smiles>CCN(CC)c1ccc2c(c1)Oc1c(cc3c(-c4ccccc4)c4ccc(=O)c(C)c-4oc3c1C)C2c1ccccc1-c1nnc(Nc2ccccc2)o1</smiles>

曹晓群课题组 ${ }^{[84]}$ 在利用罗丹明内酰胺环的关-开基 础上同时引进 FRET 机理设计了比率型苂光探针 57. 在 
无 HClO 时, 通过 PET 过程将罗丹明能量转移到咪唑并 吡啶基团上，当与 $\mathrm{ClO}^{-}$接触后 PET 过程被阻止，咪唑 并吡啶基团能量通过 FRET 过程转移到罗丹明基团, 罗 丹明开环, 苂光主要以罗丹明 $560 \mathrm{~nm}$ 的发射为主. 探针 具有选择性强、灵敏度高、检测限低 $\left(24 \mathrm{nmol} \cdot \mathrm{L}^{-1}\right)$ 和响 应时间短、溶酶体靶向性好、细胞毒性低等特点, 被成 功用于内源性 $\mathrm{ClO}^{-}$的检测.<smiles>CCN(CC)c1ccc2c(c1)Oc1cc(N3CCN(C(=O)c4ccn5c(C(C)(C)C)nc(Cl)c5c4)CC3)ccc1C21c2ccccc2C(=S)N1N</smiles>

基于这一理念, 赵宝祥课题组 ${ }^{[85 ~ 87]}$ 设计并合成探 针 58 60 (Scheme 9). 探针 58 由罗丹明与菜酰亚胺两 个荧光团组成, 在自由态下仅发出荎酰亚胺的苂光, 当 与 $\mathrm{ClO}^{-}$接触后, 罗丹明内环被打开的同时苂光显现, 萗 酰亚胺苂光团能量通过跨键能量转移(TBET)机理转移 到罗丹明母核, 罗丹明在 $582 \mathrm{~nm}$ 处的发射增加, 而萗酰
亚胺在 $532 \mathrm{~nm}$ 处的发射减少。探针 59 由罗丹明硫代酰 肼和䒺甲酰基构建硫-肼的结构，与 $\mathrm{HClO}$ 反应时，单硫 代一双肼可转化为 1,2,4-噁二唑, 这不仅确保了供体和受 体与电子共轭键连接, 而且还导致螺环开环和苂光团苂 光发射, $440 \mathrm{~nm}$ 处苂光强度下降, $585 \mathrm{~nm}$ 处苂光强度增 强, 并成功应用于 RAW264.7 细胞苂光成像. 探针 60 是 通过刚性结构哌嗪作为连接基团，将香豆素类和罗丹明 类苂光团连接，用于酸性条件下检测 $\mathrm{HClO}$, 在与 $\mathrm{ClO}^{-}$ 反应后, 罗丹明内酰胺环打开, 香豆素能量经过 FRET 过程转移到罗丹明母核, $470 \mathrm{~nm}$ 处苂光强度减弱, 580 $\mathrm{nm}$ 处苂光强度增强. 三个探针均具有选择性高、反应迅 速、细胞毒性小及细胞膜透性好等特点, 适合于在活细 胞中内源性 $\mathrm{ClO}^{-}$成像.

第三种类型是基于氧化含硫族化合物(硫、硒和碲 元素)设计的新型苂光探针. 林伟英课题组 ${ }^{[88]}$ 合成了一 种用于细胞和斑马鱼体内 $\mathrm{ClO}^{-}$检测的“打开型” $\mathrm{PZ}-\mathrm{HA}$ 分子荧光探针 61. 该探针以吩噻嗪作为苂光团, 二氰甲 基-4-吡喃作为给电子基团，在近红外区有可控的发射 波长, 吩噻嗪在硫原子处有较高的电子云密度, 在与 $\mathrm{ClO}^{-}$接触后，有效地氧化生成亚砜(Eq. 26), 使其产生 优良的比率苂光信号, $605 \mathrm{~nm}$ 处苂光出现 80 倍增强(图 $6)$.
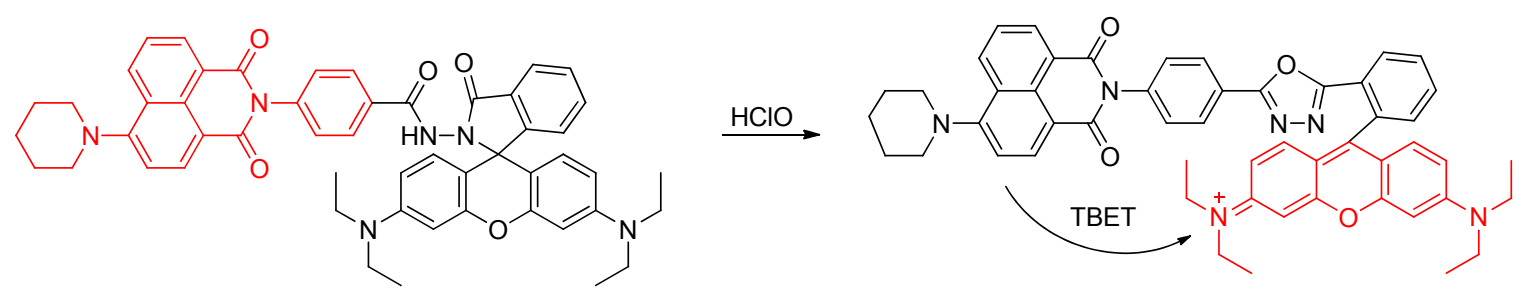

58<smiles>CCN(CC)c1ccc2c(c1)Oc1cc(N(CC)CC)ccc1C21c2ccccc2C(=S)N1NC(=O)c1ccc2cc(N(C)C)ccc2c1</smiles>

$\stackrel{\mathrm{HClO}}{\longrightarrow}$<smiles>CCN(CC)c1ccc2c(-c3ccccc3-c3nnc(-c4ccc5cc(N(C)C)ccc5c4)o3)c3ccc(=[N+](CC)CC)cc-3oc2c1</smiles><smiles>CCN(CC)c1ccc2c(c1)Oc1cc(N3CCN(C(=O)c4cc5ccc(N(CC)CC)cc5oc4=O)CC3)ccc1C21c2ccccc2C(=S)N1N</smiles>

60

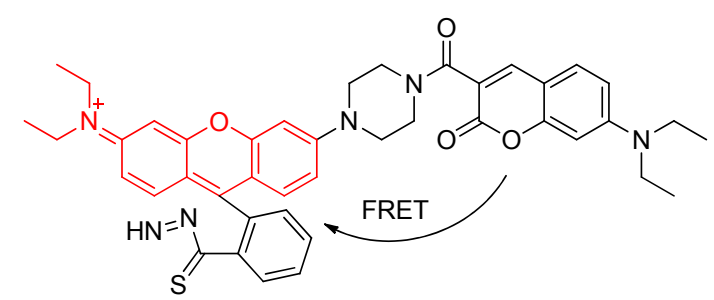

图式 9 探针 58 $\sim 60$ 对 $\mathrm{HClO}$ 的响应机理

Scheme 9 Reaction mechanism of probes $\mathbf{5 8} \sim \mathbf{6 0}$ to $\mathrm{HClO}$ 


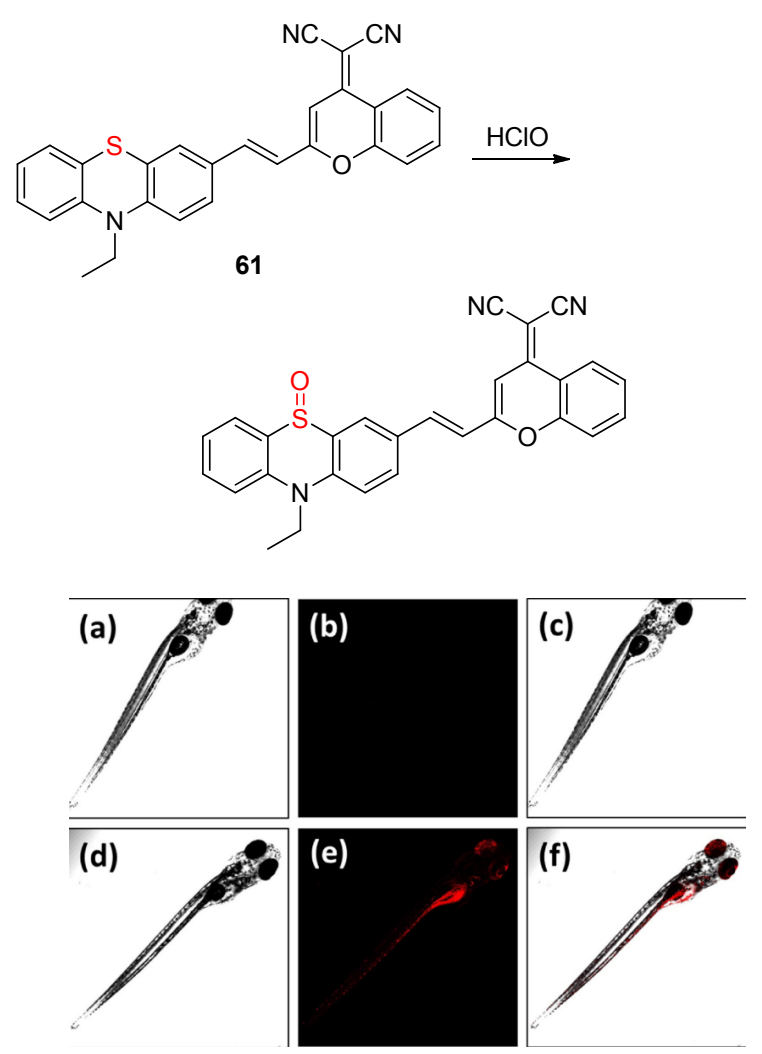

图 6 探针 61 用于斑马鱼体内检测次氯酸及苂光成像

Figure 6 Imaging of hypochlorous acid in zebrafish treated with probe $\mathbf{6 1}$

基于此原理, Gupta 课题组 ${ }^{[89]}$ 报道了探针 62, 该探 针为近红外苂光探针, 作者在 BODIPY 骨架的 C-3 位置 上引入了吩噻嗪基, 保证了分子中的延伸共轭, 在与 $\mathrm{ClO}^{-}$接触后, 吩噻嗪基上的硫被氧化(Eq. 27), $610 \mathrm{~nm}$ 处荧光强度增强 72 倍, 为 $\mathrm{ClO}^{-}$的检测提供依据. 叶勇 课题组 ${ }^{[90]}$ 介绍了一个靶向检测溶酶体中 $\mathrm{ClO}^{-}$的双光子 荧光探针 63. 该探针以䒬酰亚胺为荧光团, 在与 $\mathrm{ClO}^{-}$ 接触后, $\mathrm{S}$ 被氧化发生分子内电荷转移(Eq. 28), $505 \mathrm{~nm}$ 处荧光强度减弱, 其还具有优良的选择性、灵敏度和可 肉眼检测等优点, 检测限为 $0.674 \mu \mathrm{mol} \cdot \mathrm{L}^{-1}$, 并被成功 在 MCF-7 细胞和 4T1 细胞实现次氯酸的检测成像.
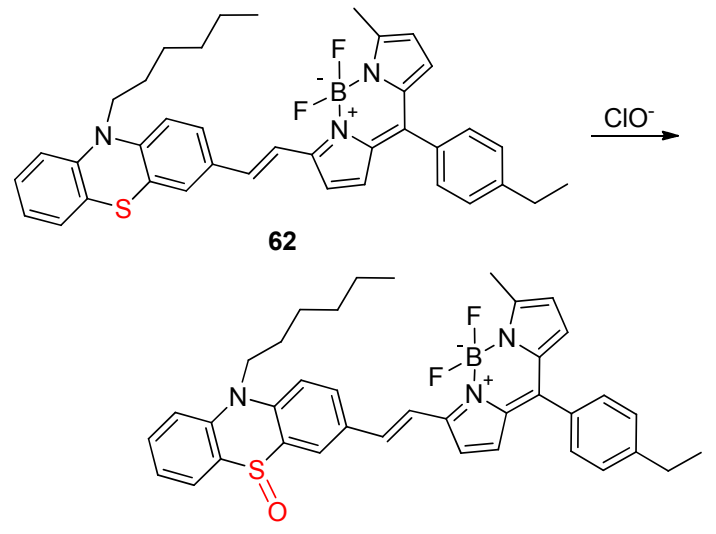

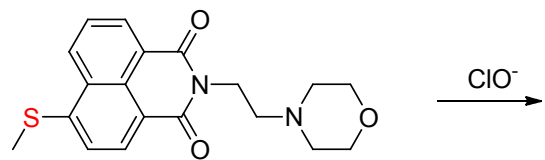

63<smiles>CS(=O)c1ccc2c3c(cccc13)C(=O)N(CCN1CCOCC1)C2=O</smiles>

通过对硒的氧化, 2013 年, 江华课题组 ${ }^{[9]}$ 设计并合 成了探针 64 和 64' (Scheme 10). 由于大的共轭基团被破 坏，在与 $\mathrm{ClO}^{-}$反应前探针分子没有荧光，当向探针溶液 中加入 $\mathrm{ClO}^{-}$后, 探针分子中的苯硒经过一步氧化转变 成苯硒亚砜，苯硒亚砜再经过消除反应形成香豆素荧光 团, 从而荧光恢复. 由于甲基的位阻影响，探针 64' 比 64 探针检测限高, 探针 64 具有高的灵敏度 $(<2 s)$ 和低 的检测限 $\left(10 \mathrm{nmol} \cdot \mathrm{L}^{-1}\right)$, 能够实时检测 $\mathrm{ClO}^{-}$的生成, 并 被成功用于细胞内活体成像. 同样利用硒的氧化前后分 子的苂光变化, Churchill 课题组 ${ }^{[92,93]}$ 设计并报道了两个 基于 BODIPY 衍生物的“打开型”苂光探针 65 和 66 . 与 64 和 64' 消除机理不同, 与 $\mathrm{HClO}$ 接触后, 化合物 65 和 66 内的硒元素被氧化，探针内的 PET 过程被禁止，荧光 团处于 $526 \mathrm{~nm}$ 的苂光恢复. 65 和 66 均是引入苯基硒基 团对母核苂光进行淬灭, 同时 $\mathrm{Cl}$ 元素的引入又降低了 背景荧光，使检测限进一步降低. 两个探针都具有分辨 率高、检测限低和响应时间快等优点. 前者成功用于细

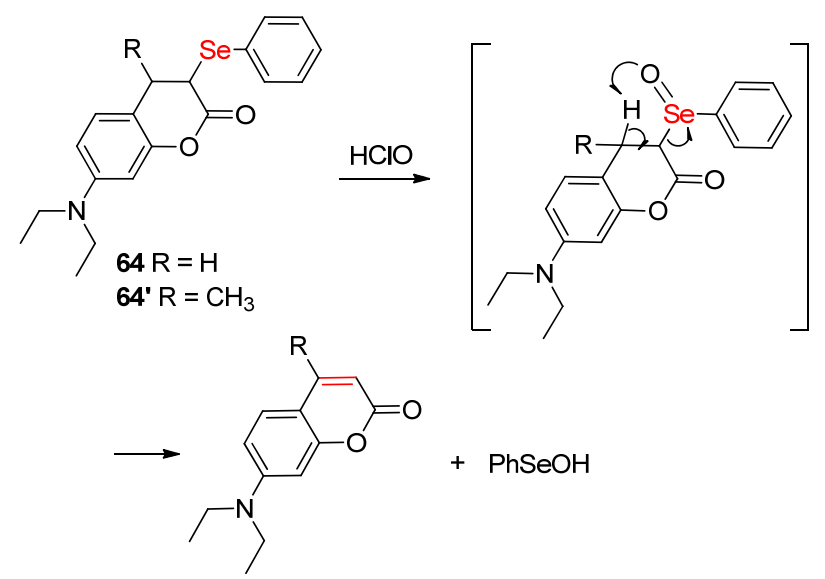

图式 10 探针 64 对 $\mathrm{HClO}$ 的响应机理

Scheme 10 Response mechanism of probe 64 to $\mathrm{HClO}$

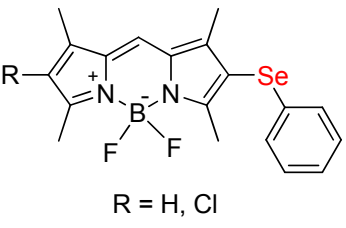

65

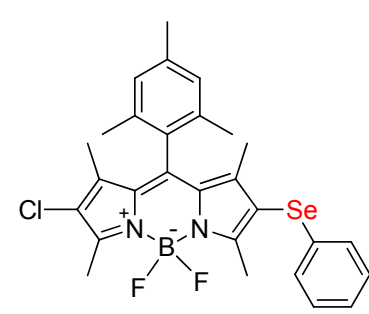

66 
胞 RAW 264.7 和 MCF-7 中 HClO 检测, 且对细胞活性 无影响, 可作为活体细胞成像的较好的探针. 后者探针 荧光强度在 $1 \sim 2 \mathrm{~min}$ 内达到最大值, 检出限低(19.6 $\left.\mathrm{nmol} \cdot \mathrm{L}^{-1}\right)$, 与其它 RNS 信号相比, 荧光增强幅度为 110 倍.

通过氧化酰肼反应, 梁高林课题组 ${ }^{[94]}$ 报道了一种 被苯甲酰肼苂光素抑制苂光的 $D$-苂光素 67 , 用于体外 $\mathrm{ClO}^{-}$的检测 (Eq. 29). 探针 67 被 $\mathrm{ClO}^{-}$氧化后再水解产生 具有苂光性的苂光素酶, $560 \mathrm{~nm}$ 处荧光达到峰值, 具有 选择性高 $\left(0 \sim 62.5 \mu \mathrm{mol} \cdot \mathrm{L}^{-1}\right)$ 和检测限低 $(0.705 \mu \mathrm{mol} \cdot$ $\mathrm{L}^{-1}$ )等优点, 并实现体外活 MDA-MB-231 细胞和小鼠 MDA-MB-231 中的 $\mathrm{ClO}^{-}$成像.<smiles>CC(C)Cc1ccccc1C(=O)NNC(=O)c1ccc2nc(-c3nc4cc(O)ccc4s3)sc2c1</smiles>

67<smiles>O=C(O)c1ccc2nc(-c3nc4cc(O)ccc4s3)sc2c1</smiles>

除了以上反应类型外, 还发展了其余类型的苂光探 针. 问良国和朱宝存课题组 ${ }^{[95]}$ 报道了一种通过分子内 电荷转移用于生物体中 $\mathrm{ClO}^{-}$检测的比率型苂光探针 68 (Eq. 30). 该探针以菜二甲酰亚氨为苂光团, 4-位引入含 硫嫝基团作为响应基团, 与 $\mathrm{HClO}$ 作用后, 柔性链部分 成环, $533 \mathrm{~nm}$ 处苂光降低, $473 \mathrm{~nm}$ 处苂光增强, 实现了 比率型检测. 该探针具有检测范围广、选择性强和检测 限低(3.9 nmol• $\left.\mathrm{L}^{-1}\right)$ 等优点, 被成功用于细胞 RAW 264.7 内源性 $\mathrm{ClO}^{-}$检测.

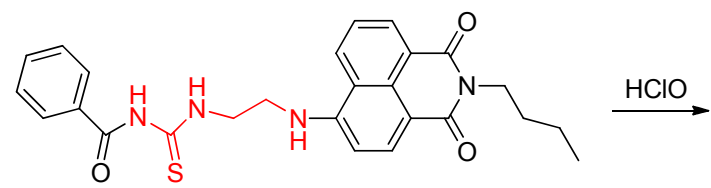

68

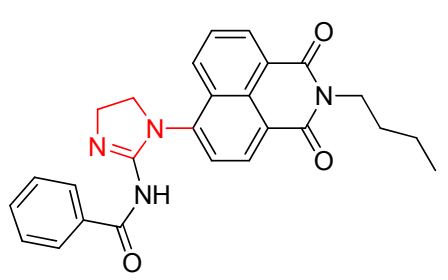

韩益锋课题组 ${ }^{[96]}$ 报道了一例基于 ESIPT 原理用于 水溶液中 $\mathrm{ClO}^{-}$检测的苂光探针 69. 该探针以 2-(2'-差基 苯基)苯并噻唑为苂光团, 引进偶氮基团抑制苂光团的 荧光发射, 在与 $\mathrm{ClO}^{-}$接触后 $\mathrm{N}=\mathrm{N}$ 被氧化破坏(Eq. 31), $466 \mathrm{~nm}$ 处苂光强度逐渐增强, 具有制备简单、水溶性
好、对 $\mathrm{HClO}$ 的选择性和灵敏度高及检出限低(13.2 $\left.\mathrm{nmol} \cdot \mathrm{L}^{-1}\right)$ 的独特优点.
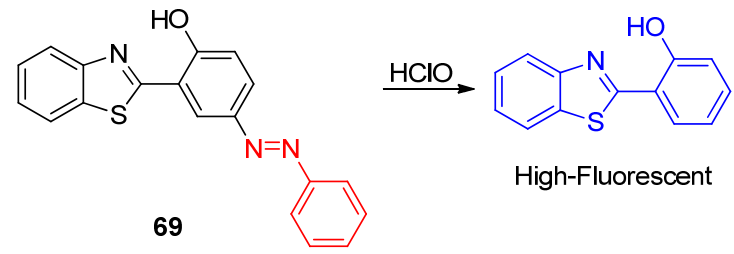

陈建和张培盛课题组 ${ }^{[97]}$ 根据 ICT 和 FRET 原理设计 并合成了用于 $\mathrm{ClO}^{-}$检测的探针 70. 该探针以䒺酰亚胺 为荧光团，电子供体硫腿基团与 $\mathrm{ClO}^{-}$接触后被氧化，转 化为咪唑啉基(吸电子基团) (Eq. 32), 荧光发射出现显 着的蓝移 $(>100 \mathrm{~nm})$. 且水分散性能好、响应速度快 $(<$ $40 \mathrm{~s}$ ), 灵敏度(检出限 $1.75 \mathrm{nmol} \cdot \mathrm{L}^{-1}$ ) 和选择性高, 体内 成像实验表明探针 70 能够用于斑马鱼模型内源性 $\mathrm{ClO}^{-}$ 生成的可视化检测.

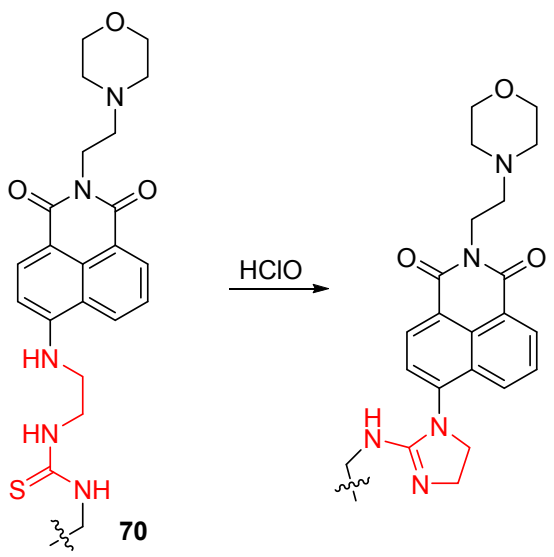

李金和韩益锋课题组 ${ }^{[98]}$ 设计并报道了一个用于 $\mathrm{ClO}^{-}$检测的 BODIPY 类 PHC-1 苂光探针 71. 该探针通 过在侧链引入 $\mathrm{C}=\mathrm{N}$, 在与 $\mathrm{ClO}^{-}$接触后侧链被氧化分子 内成环(Eq. 33), $508 \mathrm{~nm}$ 处荧光强度增强, 从而实现对 $\mathrm{ClO}^{-}$的检测.
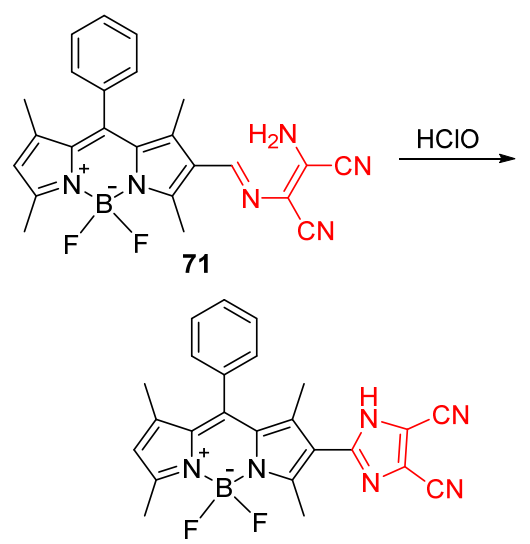

阴彩霞课题组 ${ }^{[99]}$ 直接利用 2 -荎酚及其衍生物作为 
探针报道 2 个用于 $\mathrm{ClO}^{-}$检测的比率型苂光探针 72. 探 针在次氯酸强氧化作用下, 酚羟基分子间发生脱水反应 进而偶联, 共轭结构延伸, 探针 72A 在 $430 \mathrm{~nm}$ 处苂光强 度增强, 探针 72B 在 $520 \mathrm{~nm}$ 处苂光强度增强, 颜色前后 变化肉眼可见. 探针 72A 和 72B 检测限分别为 81 和 49 $\mathrm{nmol} \cdot \mathrm{L}^{-1}$, 二者均具有高选择性和高灵敏度等优点.

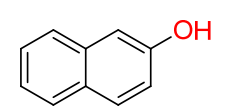

72A

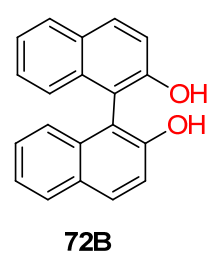

72B

\section{2 用于过氧化氢检测的荧光探针}

过氧化氢作为活性氧中的强氧化剂, 也是氧代谢的 产物之一. 随着科研工作者的研究, 发现该化合物在多 种信号传递过程中作为信号分子起到关健作用, 另外还 发现其在氧化应激过程中同样起到重要作用. 过氧化氢 的水平过量将会引起多种疾病, 例如心血管疾病、神经 性疾病、和癌症等. 因此, 使用苂光探针选择性检测 $\mathrm{H}_{2} \mathrm{O}_{2}$ 并进一步理解 $\mathrm{H}_{2} \mathrm{O}_{2}$ 在生物体中的生成, 并阐述其 在生命过程中的作用是非常重要的. 硼酸酯是广泛用于 $\mathrm{H}_{2} \mathrm{O}_{2}$ 识别的一类基团, 主要利用了 $\mathrm{H}_{2} \mathrm{O}_{2}$ 诱导的化学选 择性苯基硼酸-苯酚的转化 ${ }^{[100,101]}$.

最早将硼酸酯脱保护应用于苂光探针检测 $\mathrm{H}_{2} \mathrm{O}_{2}$ 的 是 Chang 课题组 ${ }^{[102]}$. 该课题组在 2004 年将硼酸酯与荧 光素结合, 设计合成了一例对 $\mathrm{H}_{2} \mathrm{O}_{2}$ 增强型苂光探针. 该 探针加入 $\mathrm{H}_{2} \mathrm{O}_{2}$ 后苂光增强大于 500 倍, 远大于其他 ROS 和 RNS 加入后荧光强度的变化, 并且作者阐述了 苯基硼酸-苯酚的转化机理. 随后的几年时间里, 该课 题组在这一理论的基础上又设计合成了一系列荧光探 针, 并将其运用到线粒体中 $\mathrm{H}_{2} \mathrm{O}_{2}$ 的测试. 但是前期化合 物的绝对苂光强度较小, 在生物样品中的测试受到了影 响.

近年来, 以各种荧光团为骨架利用该机理设计的分 子探针越来越多.

郡士俊课题组 ${ }^{[103,104]}$ 报道了一例水溶性 BODIPY 类 荧光探针 73, 并将其用于 $\mathrm{H}_{2} \mathrm{O}_{2}$ 的快速检测. 未与 $\mathrm{H}_{2} \mathrm{O}_{2}$ 结合之前该化合物中发生季铵盐氮原子向 BODIPY 的 PET 作用, 因此化合物几乎没有荧光; 探针分子与 $\mathrm{H}_{2} \mathrm{O}_{2}$ 结合以后, PET 被阻断, BODIPY 的苂光恢复. 该探针能 够用于 $\mathrm{Hepg} 2$ 细胞中外源性的 $\mathrm{H}_{2} \mathrm{O}_{2}$ 分布, 及天使鱼在 外源性 $\mathrm{H}_{2} \mathrm{O}_{2}$ 存在下的活体荧光成像. 该课题组于 2016 年设计合成了另一例嗍酸酯水解机理的 $\mathrm{H}_{2} \mathrm{O}_{2}$ 苂光探针 74. 与探针 73 发光机理类似, 探针 74 发生喹啉的季胺 氮原子向咔唑的 PET 作用导致本身没有荧光, 与 $\mathrm{H}_{2} \mathrm{O}_{2}$
反应后 PET作用消失，咔唑基团的荧光恢复(Eq. 34). 作 者成功利用探针 74 含有的线粒体靶向位点季氨基哇啉 检测 Hela 细胞中内源性 $\mathrm{H}_{2} \mathrm{O}_{2}$ 并进行了苂光成像.
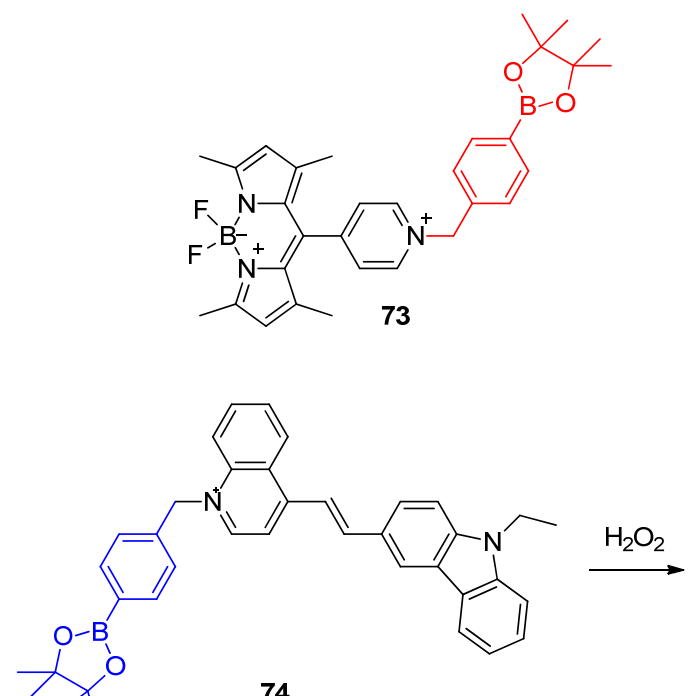

74

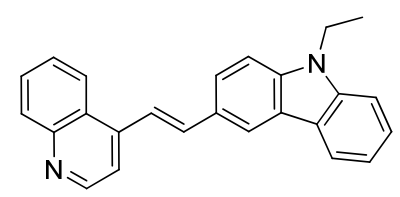

探针 75 是唐波课题组 ${ }^{[105]}$ 设计合成的一例以四苯乙 烯为苂光母核的 $\mathrm{H}_{2} \mathrm{O}_{2}$ 荧光探针. 该探针基于聚集诱导 发光(AIE)机理, 当体系中存在 $\mathrm{H}_{2} \mathrm{O}_{2}$ 时, 探针中的苯嗍 酸酯基团转变成苯酚基团(Eq. 35), 增加了四苯乙烯的 聚集作用, 体系 $500 \mathrm{~nm}$ 处的苂光强度增加, 且与 $\mathrm{H}_{2} \mathrm{O}_{2}$ 的浓度 $\left(10 \sim 200 \mu \mathrm{mol} \cdot \mathrm{L}^{-1}\right)$ 呈线性关系, 检测限低至 $0.52 \mu \mathrm{mol} \cdot \mathrm{L}^{-1}$. 该探针已经被成功用于小鼠 RAW 264.7 细胞中的 $\mathrm{H}_{2} \mathrm{O}_{2}$ 检测成像. 林伟英课题 组 ${ }^{[106]}$ 同样利用 嗍酸酯的水解反应合成了探针 76. 该探针基于扭曲的 分子内电荷转移(TICT) 底物本身没有苂光, 与 $\mathrm{H}_{2} \mathrm{O}_{2}$ 反 应后, 迅速形成一个具有刚性平面的稳定大 $\pi$ 体系(Eq. 36), 随着 $\mathrm{H}_{2} \mathrm{O}_{2}$ 浓度上升荧光强度增强, $400 \mathrm{~nm}$ 激发波

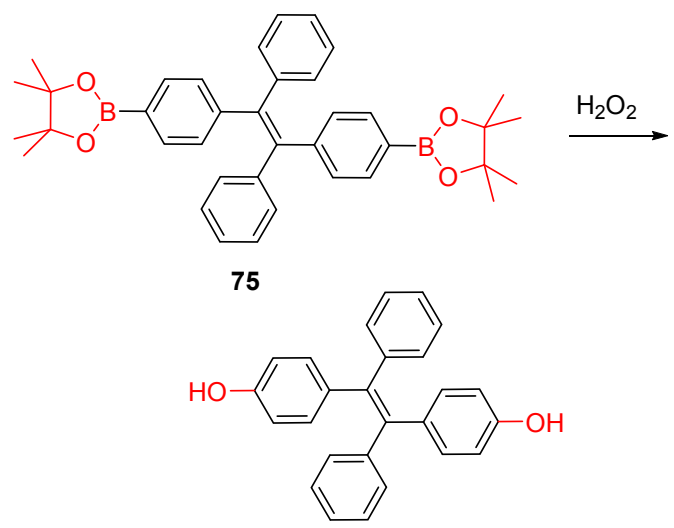




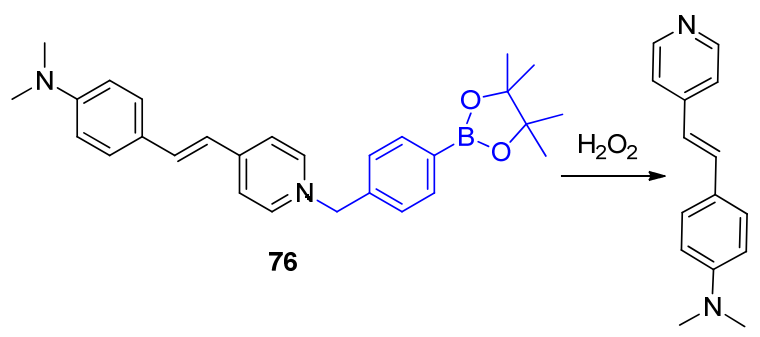

(36)

长下显现绿色苂光. 该探针还具有检测线粒体粘稠度的 效应, 粘稠度升高分子内旋转受到抑制, $500 \mathrm{~nm}$ 激发波 长下显现红色荧光. 该探针中的吡啶具有低细胞毒性及 优异的膜穿透性等优点, 可以靶向进入线粒体, 成功应 用于 $\mathrm{HeLa}$ 细胞和 RAW 264.7 细胞的内源性 $\mathrm{H}_{2} \mathrm{O}_{2}$ 检测.

Chang 课题 ${ }^{107]}$ 利用嗍酸对 $\mathrm{H}_{2} \mathrm{O}_{2}$ 的特异性响应通过 正电子成像术设计了一个用于 $\mathrm{H}_{2} \mathrm{O}_{2}$ 检测的探针 77 (Eq. 37). 过氧笼- $\left[{ }^{18} \mathrm{~F}\right]$ 氟脱氧胸苷作为荧光团和靶向基团, 在与 $\mathrm{H}_{2} \mathrm{O}_{2}$ 反应后, 硼酸基团被水解, 苂光强度增强(图 7), 具有高选择性、高灵敏度、低细胞毒性和高细胞膜 渗透性，预计可用于临床.
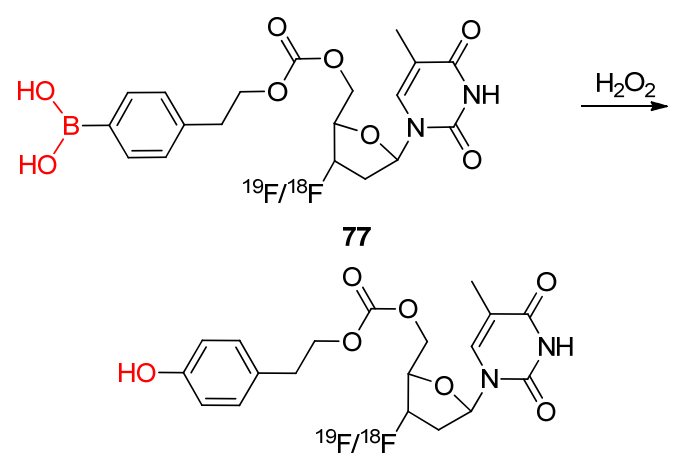

(37)

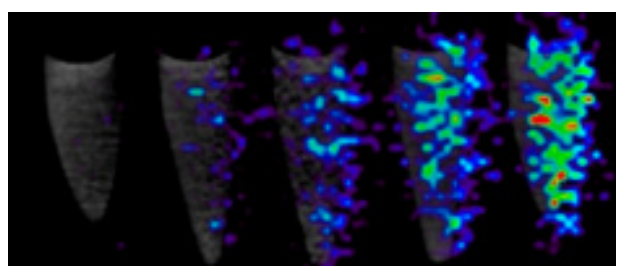

图 7 探针 77 用于肾癌细胞过氧化氢检测及苂光成像

Figure 7 Imaging of hydrogen peroxide in UOK262 renal carcinoma cells treated with probe $\mathbf{7 7}$

以单一波长处苂光强度的变化而设计的苂光探针 在使用过程中容易受到设备效率、环境条件、探针浓度 等外在因素的干扰, 从而降低苂光探针检测的选择性和 灵敏度. 而比率型苂光探针恰好克服这类缺点.

最近, 张向阳课题组 ${ }^{[108]}$ 设计了一例基于苯基硼酸苯酚机理的 $\mathrm{H}_{2} \mathrm{O}_{2}$ 苂光探针 78 (Eq. 38), 该探针未与 $\mathrm{H}_{2} \mathrm{O}_{2}$ 反应时, 在 $640 \mathrm{~nm}$ 处发射红色荧光, 当与 $\mathrm{H}_{2} \mathrm{O}_{2}$ 结 合以后发射波长蓝移至 $535 \mathrm{~nm}$, 蓝移幅度高达 $105 \mathrm{~nm}$. 且发射比值 $\left(I_{535} / I_{640}\right)$ 与 $\mathrm{H}_{2} \mathrm{O}_{2}$ 浓度呈线性关系. 该探针被
成功应用于 Hela 细胞内苂光成像.<smiles>CCN(CC)c1ccc2cc(/C=C/c3cc[n+](Cc4ccc(B5OC(C)(C)C(C)(C)O5)cc4)cc3)c(=O)oc2c1</smiles>

薛林和江华课题组 ${ }^{[109]}$ 报道了一例以 2-(2'-差基苯 基)苯并噁唑为苂光团, C-9 烷基链作为疏水尾基团的比 率型荧光探针 79 (Eq. 39). 探针 79 在表面活性剂溶液中 被表面活性剂分子包覆形成阳离子聚集体，在该聚集态 中, 分子内旋转受限从而限制了非辐射途径, 表现出强 烈的激发态分子内质子转移(ESIPT) 的过程, 在与 $\mathrm{H}_{2} \mathrm{O}_{2}$ 反应后硼酸酯基团被破坏, $405 \mathrm{~nm}$ 处苂光强度降低, 510 $\mathrm{nm}$ 处荧光强度增强. 这种聚集状态加速了探针 79 与 $\mathrm{H}_{2} \mathrm{O}_{2}$ 的响应速率, 建立了一种快速检测 $\mathrm{H}_{2} \mathrm{O}_{2}$ 的新方法. 用于 $\mathrm{H}_{2} \mathrm{O}_{2}$ 检测和检测其他物质的相关探针工作，江华 课题组 ${ }^{[110 ~ 114]}$ 在 2012 年和 2013 年在该方面也展开了很 好的工作.

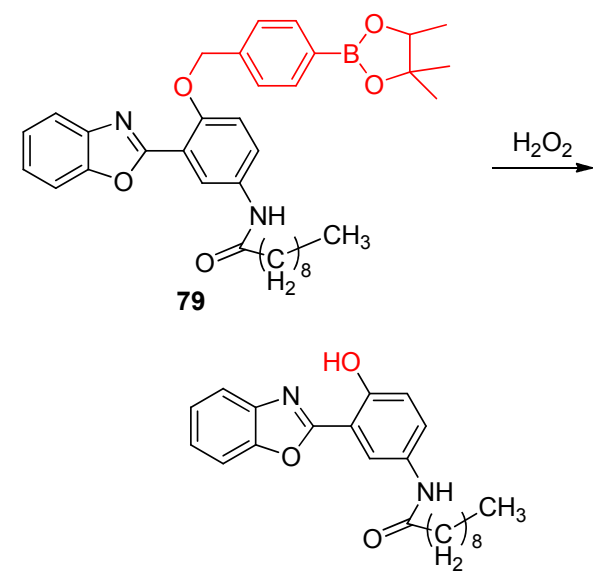

吴水珠和李文笙课题组 ${ }^{[115]}$ 开发了一种基于 FRET 机理的 $\mathrm{H}_{2} \mathrm{O}_{2}$ 检测的苂光探针 80 (Eq. 40). 带有硼酸酯基 团的萗酰亚胺连接到碳量子点上, 完整的纳米探针在 $395 \mathrm{~nm}$ 激发时在 $457 \mathrm{~nm}$ 发射出碳量子点的苂光. 与 $\mathrm{H}_{2} \mathrm{O}_{2}$ 结合后硼酸酯基团水解成苯酚基团, 此时由于 FRET 作用 $457 \mathrm{~nm}$ 处荧光强度降低, $550 \mathrm{~nm}$ 处荧光强度 增强. $\mathrm{FI}_{550 \mathrm{~mm}} / \mathrm{FI}_{457 \mathrm{~nm}}$ 的比值与 $\mathrm{H}_{2} \mathrm{O}_{2}$ 浓度呈良好的线性 关系. 探针还具有响应快速、检测限低 $\left(0.5 \mu \mathrm{mol} \cdot \mathrm{L}^{-1}\right)$ 、 毒性低和灵敏度高等优点, 被成功用于斑马鱼药物氧化 损伤产生的 $\mathrm{H}_{2} \mathrm{O}_{2}$ 检测. 


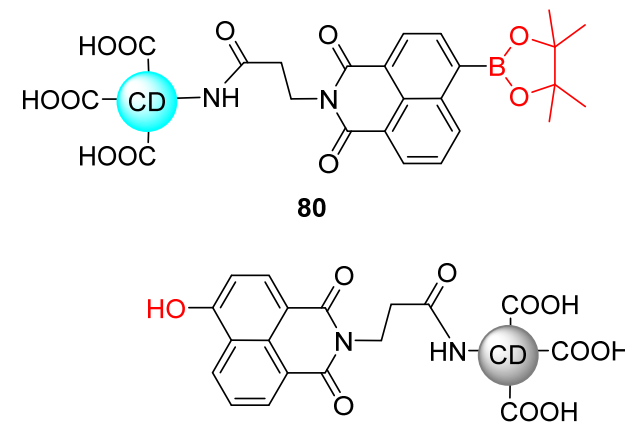

$\mathrm{H}_{2} \mathrm{O}_{2}$

$\operatorname{Kim}$ 课题组 ${ }^{[116]}$ 报道了一种用于组织器官中 $\mathrm{H}_{2} \mathrm{O}_{2}$ 检 测的双光子比率型荧光探针 81. 该探针以 6-(苯并 $[d]$ 噻 唑-2'-基)-2-( $N, N$-二甲基氨基)菜为苂光团, 仍然以苯基 嗍酸酯作为 $\mathrm{H}_{2} \mathrm{O}_{2}$ 的响应基团, 在与 $\mathrm{H}_{2} \mathrm{O}_{2}$ 反应后, 苯基 嗍酸酯基团水解离去(Eq. 41), $455 \mathrm{~nm}$ 处苂光强度降低, $528 \mathrm{~nm}$ 处苂光强度增强，检测限低至 $4.6 \mu \mathrm{mol} \cdot \mathrm{L}^{-1}$.

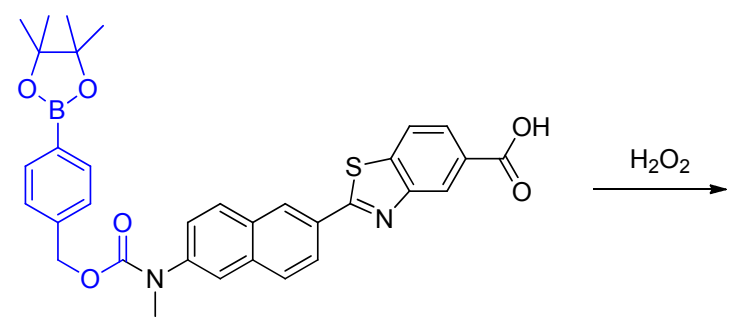

81

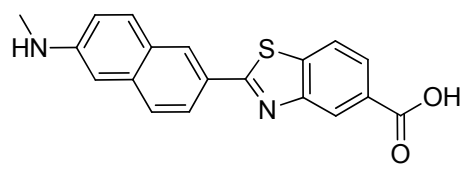

李银辉课题组 ${ }^{[117]}$ 也是利用硼酸酯水解原理设计了 苂光探针 82, 探针 82 与 $\mathrm{H}_{2} \mathrm{O}_{2}$ 反应后硼酸酯基团水解 (Eq. 42), $430 \mathrm{~nm}$ 处苂光强度增强, 随着 $\mathrm{H}_{2} \mathrm{O}_{2}$ 浓度增加 到 $80 \mu \mathrm{mol} \cdot \mathrm{L}^{-1}$, 苂光强度达到峰值, 能够用于双光子苂 光显微镜长时间检测活细胞和组织中的 $\mathrm{H}_{2} \mathrm{O}_{2}$, 成像质 量优良(图 8), 对于深入研究 $\mathrm{H}_{2} \mathrm{O}_{2}$ 在复杂生物系统中的 作用和功能有重要作用.

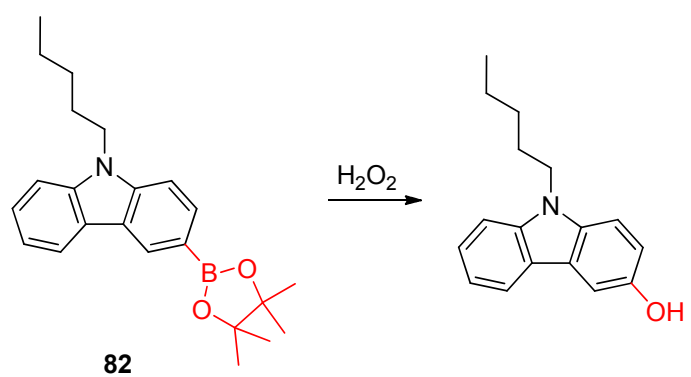

除了上面提到的硼酸酯作为响应基团的 $\mathrm{H}_{2} \mathrm{O}_{2}$ 苂光 探针外, 还发展了一系列具有其他响应基团的苂光探针 分子.

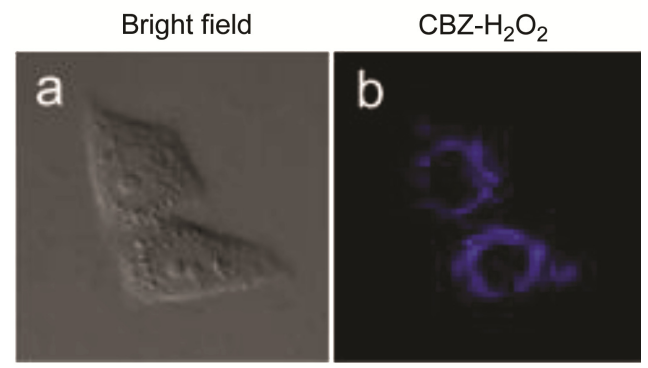

图 8 探针 82 用于 $\mathrm{HeLa}$ 细胞检测过氧化氢及苂光成像 Figure 8 Probe $\mathbf{8 2}$ for hydeogen peroxide detection and fluorescence imaging in Hela cells

张晓玲课题组 ${ }^{[118]}$ 设计并合成了一种基于羰基酰胺 水解的比率型苂光探针 83 , 用于定向检测内质网中的 $\mathrm{H}_{2} \mathrm{O}_{2}$. 探针中的过氧基团在与 $\mathrm{H}_{2} \mathrm{O}_{2}$ 反应后，过氧基团 被水解氧化脱落(Eq. 43), 新的苂光发射峰在 $540 \mathrm{~nm}$ 处 逐渐增强, $465 \mathrm{~nm}$ 处峰值逐渐减弱. 该探针可利用比值 法定量检测 $\mathrm{H}_{2} \mathrm{O}_{2}$ 的含量, 具有高选择性, 并在 $\mathrm{HeLa}$ 细 胞中实现外源性 $\mathrm{H}_{2} \mathrm{O}_{2}$ 检测成像.<smiles>CC(C)(C)N1C(=O)c2cccc3c(N)ccc(c23)C1=O</smiles>

吴水珠和曾钫课题组 ${ }^{[119]}$ 报道了一个通过磷脂包封 的比率型苂光纳米探针 $\mathbf{8 4}$, 磷脂的包封作用使探针 84 具有很好的生物相容性. 探针 84 是在葱的 6-位引入苯 乙二酮响应基团，该基团在与 $\mathrm{H}_{2} \mathrm{O}_{2}$ 接触后转变为羧基 (Eq. 44). 6-位取代基吸电能力的变化使探针分子的苂光 性质能够发生相应的变化, 因此探针 84 与 $\mathrm{H}_{2} \mathrm{O}_{2}$ 反应后 $516 \mathrm{~nm}$ 处荧光强度降低, $595 \mathrm{~nm}$ 处荧光强度增强, 检出 限为 $0.49 \mu \mathrm{mol} \cdot \mathrm{L}^{-1}$, 能够有效监测活细胞及生物体中内 源性的 $\mathrm{H}_{2} \mathrm{O}_{2}$. 此外, 在器官受损的斑马鱼模型中, 纳米 探针能够追踪 $\mathrm{H}_{2} \mathrm{O}_{2}$ 的浓度水平, 这将有助于相关疾病 的诊断, 也为判断 $\mathrm{H}_{2} \mathrm{O}_{2}$ 在相关病理过程中的作用提供 了一个潜在的工具. Sumimoto 课题组 ${ }^{[120]}$ 同样基于苯二 乙酮响应机理设计并合成了荧光素为母核的荧光探针 85, 该探针还引进了噬菌体靶向定位基团芐基鸟嘌呤. 能够在活 HEK293T 细胞、RAW 264.7 细胞实现实时成 像监测。

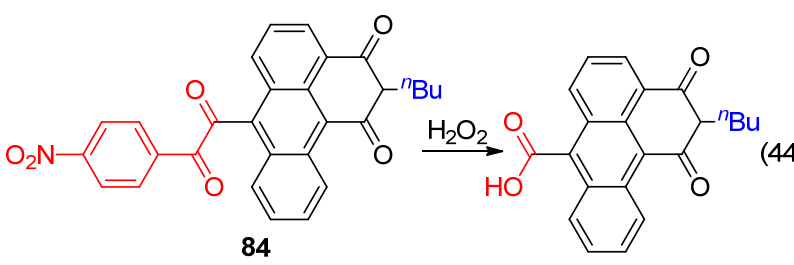


<smiles></smiles>

85

在这一领域的继续研究中, Kumar课题组 ${ }^{[121]}$ 设计并 报道了一个用于溶酶体靶向的 $\mathrm{H}_{2} \mathrm{O}_{2}$ 苂光探针 86. 该探 针中含有一个邻苯二酚作为 $\mathrm{H}_{2} \mathrm{O}_{2}$ 的响应基团, 分子内 的邻苯二酚能够发生向菜酰亚胺的 PET 作用, 分子苂光 很弱. 当与 $\mathrm{H}_{2} \mathrm{O}_{2}$ 作用后邻苯二酚的酚羟基被氧化, 分子 内 PET 被阻止(Eq. 45), 苂光团在 $537 \mathrm{~nm}$ 处苂光增强. 探针分子中吗啉基团作为溶酶体的靶向基团，该基团能 够靶向活细胞溶酶体中的 $\mathrm{H}_{2} \mathrm{O}_{2}$ 进行内源性检测, 探针 还被用于脑组织和活线虫中的 $\mathrm{H}_{2} \mathrm{O}_{2}$ 检测, 因此, 该探针 可能是检测 $\mathrm{H}_{2} \mathrm{O}_{2}$ 及相关病理反应的有效工具.

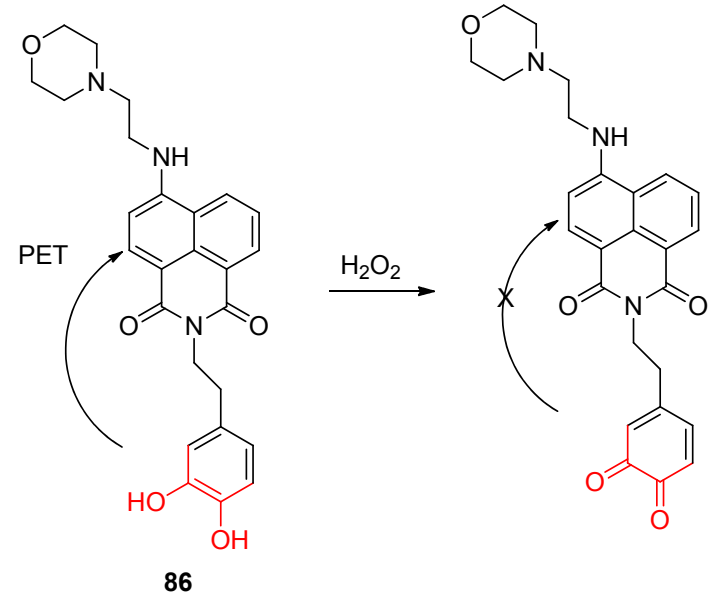

(45)

2014 年, 余孝其课题组 ${ }^{[122]}$ 设计合成了 “打开” 型 含硒探针 87 (Eq. 46), 探针在 $\mathrm{H}_{2} \mathrm{O}_{2}$ 作用下, 硒原子被氧 化成硒氧化物, 本身的 PET 作用受到抑制, 形成聚集体 从而发生 AIE 型荧光. 荧光强度与 $\mathrm{H}_{2} \mathrm{O}_{2}$ 浓度成正比且 具有良好的选择性, 其他 ROS/RNS 都不能引起探针 87 的苂光变化. Shanmugapriya 课题组 ${ }^{[123]}$ 介绍了一种含硫 取代基取代苯胺的嘲烷染料苂光探针 88 (Eq. 47), 在与 $\mathrm{H}_{2} \mathrm{O}_{2}$ 接触过程中, 含硫取代基被快速氧化, 该探针具有 响应速度快、灵敏度高等优点, 并成功应用于 HeLa 细 胞在生理条件下的 $\mathrm{H}_{2} \mathrm{O}_{2}$ 成像.

上述 $\mathrm{H}_{2} \mathrm{O}_{2}$ 检测的荧光探针都是基于氧化机理, 而 亲和取代反应是和氧化机理同等重要的一种机理, 并且

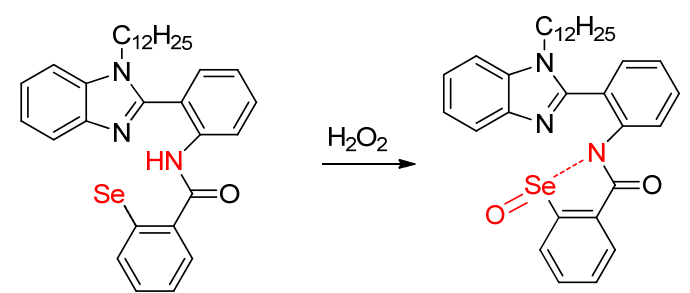

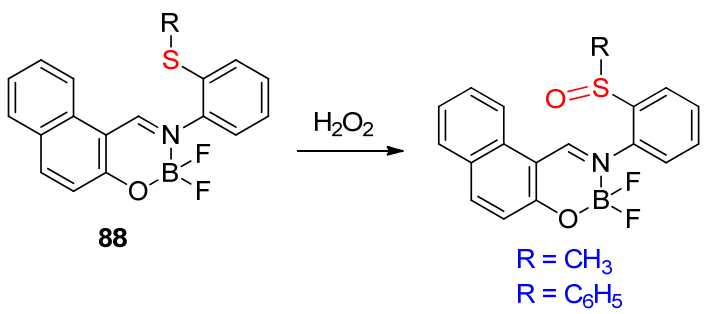

更加容易避免其他 ROS/RNS 的干扰. 战付旭课题组 ${ }^{[124]}$ 介绍了一种基于此机理设计的 $\mathrm{H}_{2} \mathrm{O}_{2}$ 荧光探针 89 (Eq. 47). 该探针包含三个基本基团: 氯原子、叠氮基团和含 有活性羰基的内酰胺环, 在与 $\mathrm{H}_{2} \mathrm{O}_{2}$ 反应后, 叠氮集团脱 落, 内酰胺环打开, $560 \mathrm{~nm}$ 处苂光显现. 探针具有高选 择性和较宽的浓度 $\left(0 \sim 400 \mu \mathrm{mol} \cdot \mathrm{L}^{-1}\right)$ 检测范围, HeLa 细 胞的初步成像表明具有生物系统利用潜能(图 9). 作者 又将氯原子、叠氮基团分别换成其他原子及基团，新形 成的化合物均失去了对 $\mathrm{H}_{2} \mathrm{O}_{2}$ 的响应，原因仍需探索.
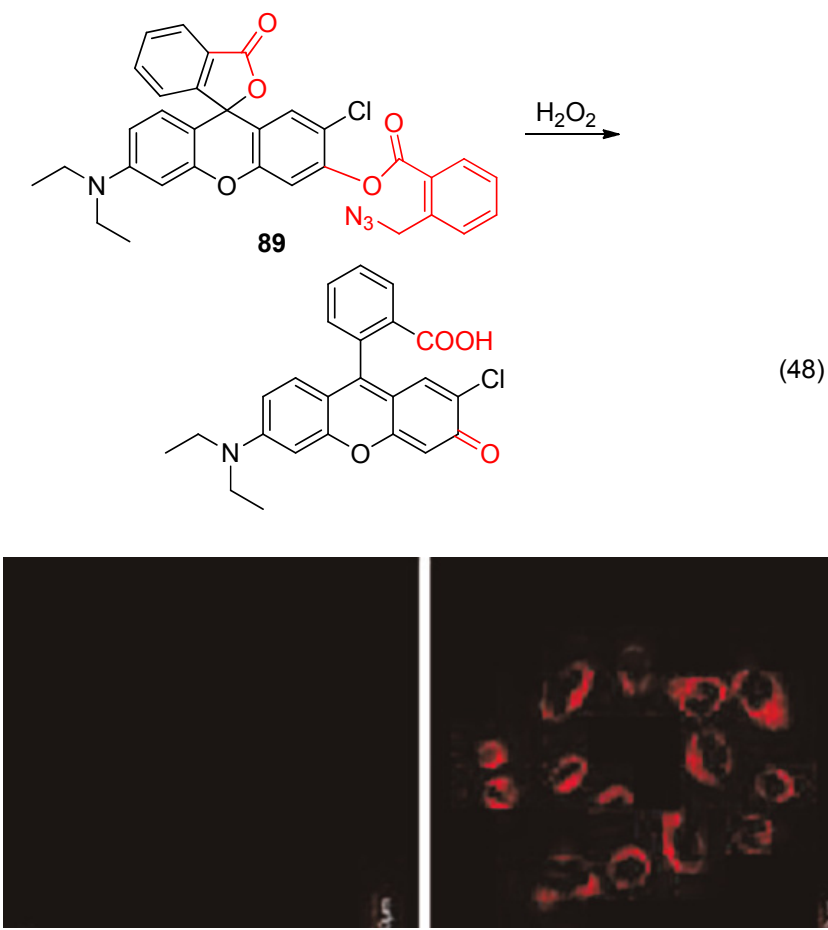

图 9 探针 89 用于 $\mathrm{HeLa}$ 细胞过氧化氢检测及苂光成像 Figure 9 Imaging of hydrogen peroxide in Hela cells stained with the probe $\mathbf{8 9}$ 


\section{3 用于羟基自由基和超氧阴离子的检测}

羟基自由基 $(\cdot \mathrm{OH})$ 现在被认为是最具破坏性的一种 ROS, 众多研究表明羟基自由基也被认为是氧化应激损 伤的主要原因, 它几乎攻击所有类型的生物大分子, 并 导致不可修复的细胞损伤, 加剧生物细胞的衰老, 由于 其在体内浓度极低, 成为影响检测难度的原因之一, 这 就需要高灵敏度的检测方法 ${ }^{[125]}$. 超氧阴离子 $\left(\mathrm{O}_{2}^{-}\right)$则是 生物系统中的初级 ROS, 在细胞的传导过程中和病理 变化中都有参与. 超氧阴离子不仅是其余 ROS 的前体, 还与多数 $\mathrm{ROS}$ 的平衡水平有相关性, 例如细胞内 $\mathrm{O}_{2}^{-}$和 $\mathrm{NO}$ 浓度处于平衡状态，且总是相互作用，过量产生 $\mathrm{O}_{2}^{-}$ 会抑制 NO 的生物利用度, 导致内皮功能障碍 ${ }^{[126]}$. 对于 羟基自由基和超氧阴离子的定性定量检测尤为重要, 因 此荧光探针技术被广泛研发, 然而现如今已经设计出的 探针并不多.

刘志宏课题组 ${ }^{[127]}$ 设计并合成一个用于检测 $\cdot \mathrm{OH}$ 调 节超氧化物歧化酶水平的探针 90 (Eq. 49). 该分子探针 是以芴衍生物为苂光团, 富电子的芳香胺为响应基团的 双光子可激发分子探针, 探针是一个 “ A- $\pi-\mathrm{D}$ ” 类型化 合物, 在与 $\cdot \mathrm{OH}$ 反应后, 探针 $\mathbf{P 1} / \mathbf{P 3}$ 在 $560 \mathrm{~nm}$ 处出现苂 光峰值, P2/P4 在 $55 \mathrm{~nm}$ 处出现苂光峰值, 其中 $\mathbf{P 2}$ 表现 出较高的灵敏度(1 equiv. $\cdot \mathrm{OH}$ 下荧光强度增强 200 倍) 和特异性, 成功应用于可视化各种类型 SOD-1 参与的 生物学过程的 $\cdot \mathrm{OH}$ 变化, 也直观揭示 SOD 1 和 $\cdot \mathrm{OH}$ 水平 之间的负相关性.

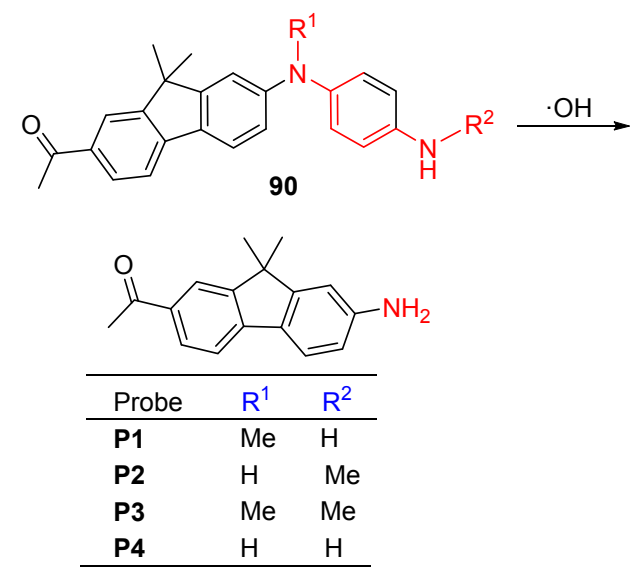

杨丹课题组 ${ }^{[128]}$ 设计并合成了一种用于体内 $\cdot \mathrm{OH}$ 检 测的荧光探针 91. 该荧光探针以荧光素为荧光团, 通过 侧链引进二碘苯酚作为响应基团, 因为 $\cdot \mathrm{OH}$ 易于与大体 积苯酚如二碘苯酚反应发生电子转移形成苯氧基自由 基(Eq. 50), $520 \mathrm{~nm}$ 处苂光强度增强. 该探针灵敏度高, 选择性强, 毒性低, 在小鼠巨噬细胞 RAW264.7 共聚焦 成像结果显示, HKOH-1 更具有潜在应用价值.

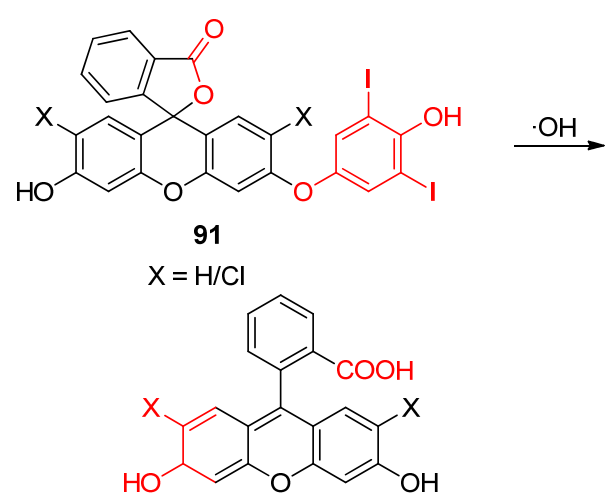

Shin 和 Tae 课题组 ${ }^{[129]}$ 基于罗丹明合成一种内酰胺 环苂光探针 92. 该探针内酰胺环是一个吡唑结构, 在与 羟基自由基反应后内酰胺环 $\mathrm{C}-\mathrm{H}$ 被氧化抽提断裂，内 酰胺环打开, 形成一个新的吡唑结构(Eq. 51), $550 \mathrm{~nm}$ 处 产生新的苂光发射峰. 同时该探针具有优异的细胞膜穿 透性，可用于细胞内的羟基自由基的检测.

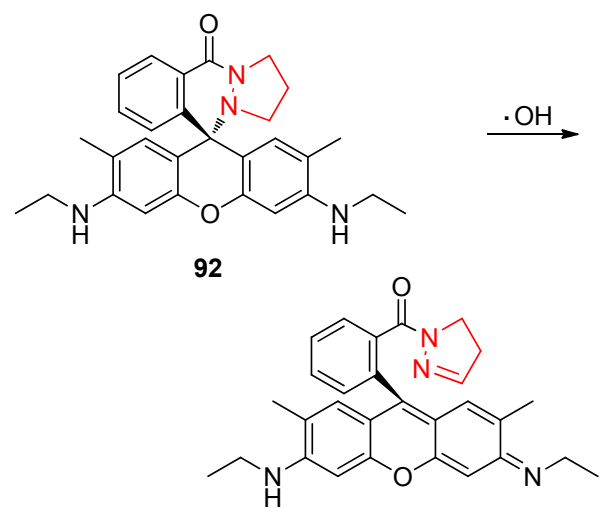

张小兵和谭蔚泓课题组 ${ }^{[130]}$ 介绍了一种基于非氧化 还原策略用于超氧阴离子 $\mathrm{O}_{2}^{-}$检测的荧光探针 $93(\mathrm{Eq}$. $52)$. 该探针是一个 D- $\pi-\mathrm{A}$ 结构, 䒺衍生物作为有效的 TP 荧光团, 三氟甲烷磺酸盐基作为 $\mathrm{O}_{2}^{-}$识别单元, 在与 $\mathrm{O}_{2}^{-}$反应后，识别基团被氧化成羟基，500 $\mathrm{nm}$ 处苂光强 度增强(235 倍), 且具有低检测限 $\left(1 \mathrm{nmol} \cdot \mathrm{L}^{-1}\right)$ 、高灵敏 度和高选择性等优点, 组织深度检测达到 $30 \sim 150$ $\mu \mathrm{mol} \cdot \mathrm{L}^{-1}$, 在 $\mathrm{O}_{2}^{-}$参与的生物和病理变化过程中具有潜 在应用价值.

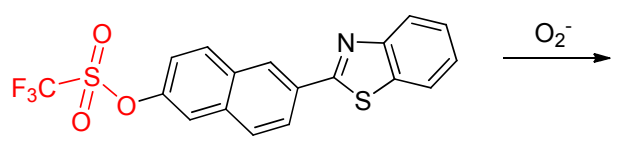

93

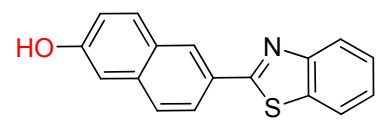

孙景志和唐本忠课题组 ${ }^{[131]}$ 设计并合成一种具有聚 
集诱导发光特性的用于 $\mathrm{O}_{2}^{-}$检测的双通道苂光探针 94 . 该探针以四苯乙烯衍生物为菼光团，二苯基-膦基为反 应基团, 连接单元为甲酚类结构, 起着荧光通道开关的 作用, 与超氧阴离子反应后分子链断裂(Eq. 53), 苂光团 聚集诱导发光, 随着 $\mathrm{O}_{2}^{-}$浓度 $\left(0 \sim 100 \mu \mathrm{mol} \cdot \mathrm{L}^{-1}\right)$ 增加, $525 \mathrm{~nm}$ 处苂光强度增强, $615 \mathrm{~nm}$ 处苂光强度减弱. 该双 通道探针克服了信号依赖于探针的浓度、微环境的变化 等影响因素, 具有高选择性, 并在 HepG 2 细胞中成功 应用, 对活细胞中 $\mathrm{O}_{2}^{-}$的检测具有重要意义.<smiles>C=C1C=C[C+]=CC(=O)C=C1C[n+]1ccc(-c2ccc(C(=C(c3ccccc3)c3ccc(OC)cc3)c3ccc(OP(=O)(c4ccccc4)c4ccccc4)cc3)cc2)cc1</smiles>

\section{4 多通道检测探针}

当一个化合物有多个反应机理时且其响应条件也 不相同时, 多通道检测的荧光探针便存在, 并能够在不 同条件下检测不同活性氮和活性氧物质.

郑静课题组 ${ }^{[132]}$ 设计并合成了能够用于 $\mathrm{ONOO}^{-}$和 $\mathrm{HClO}$ 区分检测的新型小分子荧光探针 95 . 该探针是一
种绿色发光的香豆素衍生物, 在添加 $\mathrm{ONOO}^{-}$后能够产 生三通道苂光信号 $(355,475$ 和 $575 \mathrm{~nm})$, 而与 $\mathrm{HClO}$ 作 用则只能产生双通道信号(355 和 $475 \mathrm{~nm}$ ) (Scheme 10). 该探针具有高选择性、优异的膜渗透性和低细胞毒性, 已经被成功应用在活细胞中 $\mathrm{ONOO}^{-}$和 $\mathrm{HClO}$ 的检测.

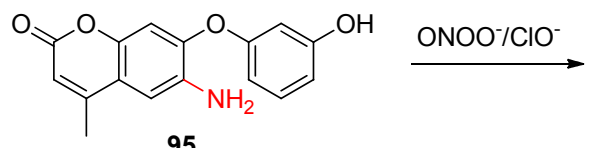

95

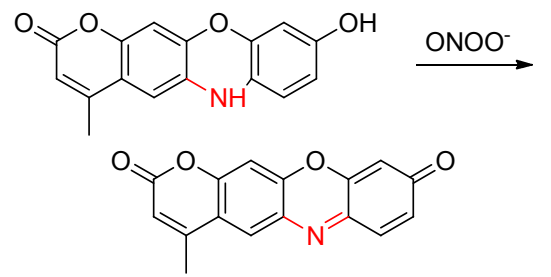

图式 10 探针 95 对 $\mathrm{HClO}$ 和 $\mathrm{ONOO}^{-}$的响应机理 Scheme 10 Working principle of probe 95 to $\mathrm{HClO}$ and $\mathrm{ONOO}$

Chellappa 课题组 ${ }^{[133]}$ 报道了一种基于罗丹明的铜 络合物用于 $\mathrm{NO} /$ 组氨酸检测的苂光探针 96. 该探针由罗 丹明 $6 \mathrm{G}$ 酰肼和 2-差基-1-菜醛反应并与 $\mathrm{Cu}(\mathrm{II})$ 络合，其 中 $\mathrm{Cu}(\mathrm{II})$ 可以看作是罗丹明的淬灭剂, 在与 $\mathrm{NO}$ 接触后 无苂光顺磁性 $\mathrm{Cu}(\mathrm{II})$ 配合物转变为抗磁性 $\mathrm{Cu}(\mathrm{II}), 548 \mathrm{~nm}$ 处苂光强度增强(Scheme 11). 由于探针的高选择性, 并 成功应用于细胞 RAW264.7 和 MCF-7 中荧光成像.

张忠平课题组 ${ }^{[134]}$ 设计并合成一个可以实时鉴别检 测 $• \mathrm{OH}$ 和 $\mathrm{HClO}$ 的荧光探针 97 (Scheme 12). 该苂光探针 以苂光素为母核，与水合肼形成五元内酰胺环导致苂光 消失，侧链引进三甘醇提高水溶性，具有双响应位点. 当激发波长为 $405 \mathrm{~nm}$ 时，探针选择性检测・OH，内酰胺

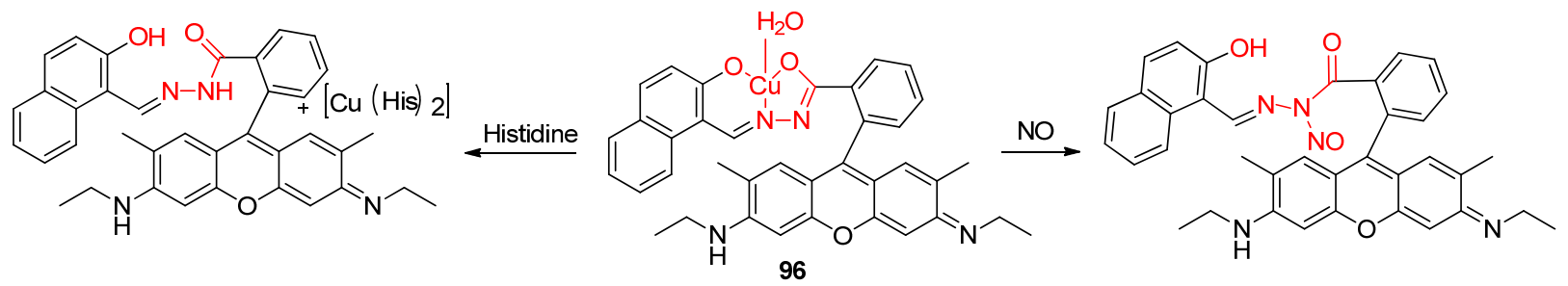

图式 11 探针 96 对 NO 和 Histidine 的响应机理 Scheme 11 Response mechanism of probe 96 to NO and Histidine<smiles>CC(O)(O)COc1ccc2c(-c3ccccc3C(=O)O)c3ccc(=O)cc-3oc2c1</smiles><smiles>CC(C)(O)COc1ccc2c(c1)Oc1cc(O)ccc1C21c2ccccc2C(=O)N1N</smiles><smiles>CC(C)(O)COc1ccc2c(c1)O/C(=C\C(=O)C(O)O)C(C=O)C2c1ccccc1C(=O)O</smiles>

图式 12 探针 97 对 $\mathrm{HClO}$ 和 $\cdot \mathrm{OH}$ 的响应机理

Scheme 12 Reaction mechanism of probe 97 to $\mathrm{HClO}$ and $\bullet \mathrm{OH}$ 
环打开, 羟基苯环断裂开环, 苂光显蓝色; 当激发波长 为 $488 \mathrm{~nm}$ 时, 选择性检测 $\mathrm{HClO}$, 内酰胺环打开, 羟基 被氧化成羰基, 荧光显绿色(图 10). 该探针具有选择性 强、水溶性高等优点, 可 RAW264.7 细胞成像及进一步 活体斑马鱼体内苂光成像.
$\mathrm{Oh}$

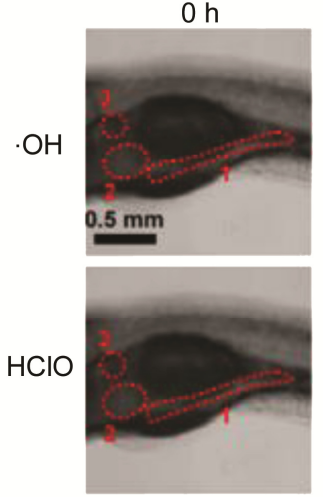

$6 \mathrm{~h}$

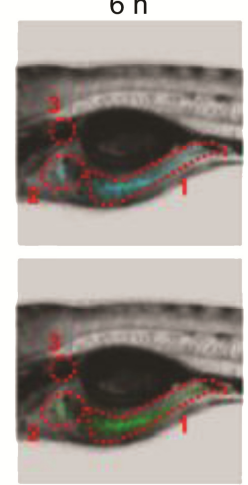

$12 \mathrm{~h}$

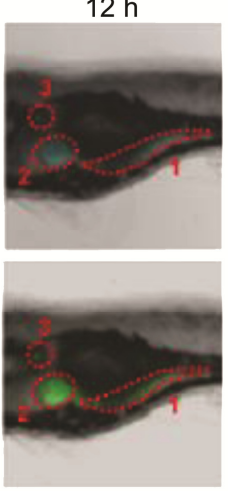

图 10 探针 97 用于斑马鱼体内羟基自由基和次氯酸检测及苂 光成像

Figure 10 Probe $\mathbf{9 7}$ for hydroxy free radical and hypochlorous acid detection and fluorescence imaging in zebrafish

陈令新课题组 ${ }^{[135]}$ 认为 $\mathrm{O}_{2}^{-}$会与 $\mathrm{H}_{2} \mathrm{~S}$ 发生反应产生 硫烷硫，因此，作者开发了一种近红外线粒体靶向探针 双通道检测的花青类苂光探针 98, 该探针允许对 $\mathrm{O}_{2}^{-}$和 $\mathrm{H}_{2} \mathrm{~S}_{\mathrm{n}}$ 进行多反应且双通道信号在 $610 \sim 700$ 和 $750 \sim 800$ $\mathrm{nm}$ 之间(Scheme 13), 通过体内体外实验作者得出结论:

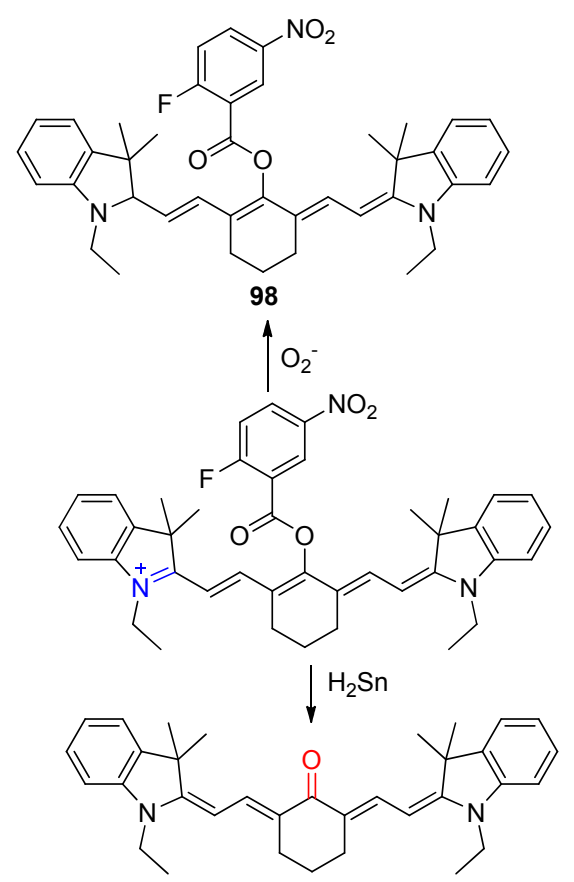

图式 13 探针 98 对 $\mathrm{O}_{2}^{-}$和 $\mathrm{H}_{2} \mathrm{Sn}$ 的响应机理 Scheme 13 Detection mechanism of probe 98 toward $\mathrm{O}_{2}^{-}$and $\mathrm{H}_{2} \mathrm{Sn}$
在 $\mathrm{O}_{2}^{-}$的存在下, $\mathrm{H}_{2} \mathrm{~S}_{\mathrm{n}}$ 会从 $\mathrm{O}_{2}^{-}$得到氧进而对机体造成 损伤.

Ang 等 ${ }^{[136]}$ 利用香豆素和罗丹明构建了一种新的比 率型荧光探针 99. 该探针以香豆素为给体, 罗丹明为受 体，二者之间通过刚性链传递能量，响应基团苯甲酰肼 能够用于 $\mathrm{HClO}$ 检测, 而邻苯二胺用于 $\mathrm{NO}$ 的检测. 二 者在与被检测物反应后, 内酰胺环打开, $505 \mathrm{~nm}$ 处荧光 强度减弱, $580 \mathrm{~nm}$ 处苂光强度增强. 两种探针均具有较 高的分析选择性和生理稳定性，在活细胞中具有良好的 生物成像性能.

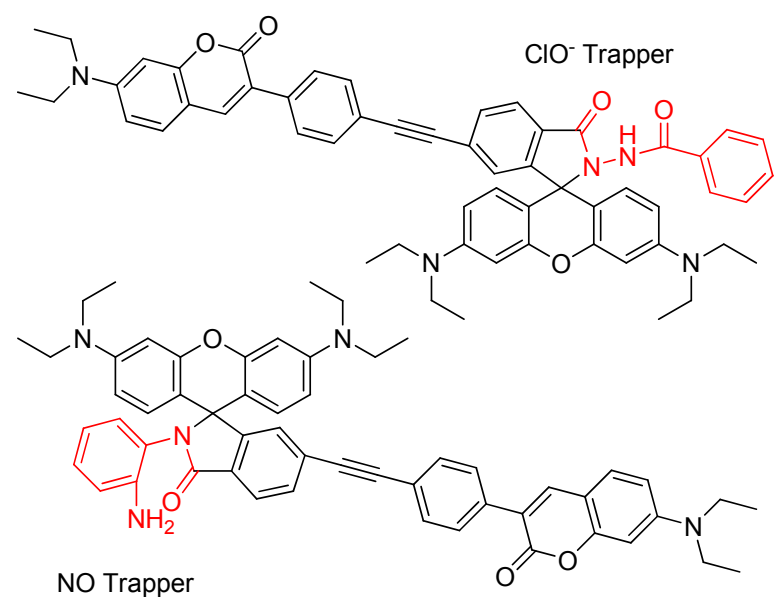

99

\section{3 结束语}

最近几年，荧光探针在 RNS 和 ROS 的检测方面发 展迅速，对生物、医药和环境等领域做出巨大贡献. 我 们探讨了自 2013 年以来开发的用于 RNS 和 ROS 检测 的荧光探针, 苂光团主要是有机小分子、聚合物和金属 络合物等, 并探讨了这两大类物种探针的设计方法、响 应机制和应用情况. 通过综述发现，检测活性氮物种的 探针多集中于过氧硝酸根和一氧化氮，检测活性氧物种 的探针多集中于过氧化氢和次氯酸上，主要原因是大部 分情况下其余物种水平浓度较低，探针的灵敏度和检测 限不足, 并且统一大类的活性物质之间可以相互转化, 无法明确标识. 虽然本文提到的探针中有一部分对 RNS 和 ROS 具有高灵敏度和特异性, 但是我们仍需进 一步研发与体内环境相容的新探针, 这一类探针的设计 中, RNS 和 ROS 在体内存在的稳定态浓度相对较低, 因 此需要从化学和生物两个方面来进行考虑: 化学方面需 要找到更多的反应机制(目前以氧化反应为主); 生物方 面除了考虑高选择性和灵敏度之外, 还需要考虑低的自 氧化性、高的光学稳定性、低细胞毒性、良好的溶解度、 细胞渗透性以及生物环境物质的低干扰. 由于低背景干 扰和低能量光对组织的高渗透性, 近红外和双光子探针 
对于 RNS 和 ROS 具有很大的生物成像潜力. 此外, 由 于在维持细胞的正常功能和健康的过程中涉及到了氧 化还原反应，因此通过监测随时间发生的可逆苂光变化 来研究细胞氧化还原生物学的氧化还原探针也是荧光 探针的研究方向之一. 综上所述, 寻找能够更好地了解 RNS 和 ROS 在细胞和生物体中的生理和病理功能的探 针将是当前生命科学研究的重要热点和难点领域之一.

\section{References}

[1] Abdel-Fattah, M. M.; Messiha, B. A.; Salama, A. A. Pharmacology 2015, 96, 167 .

[2] Hernandez-Barrera, A.; Velarde-Buendia, A.; Zepeda, I.; Sanchez, F.; Quinto, C.; Sanchez-Lopez, R.; Cheung, A. Y.; Wu, H. M.; Cardenas, L. Sensors (Basel) 2015, 15, 855.

[3] Hu, J. J.; Wong, N. K.; Ye, S.; Chen, X.; Lu, M. Y.; Zhao, A. Q.; Guo, Y.; Ma, A. C.; Leung, A. Y.; Shen, J.; Yang, D. J. Am. Chem. Soc. 2015, 137, 6837.

[4] Hu, Q.; Gao, M.; Feng, G.; Liu, B. Angew. Chem., Int. Ed. 2014, 53, 14225.

[5] Huang, Y.; Yu, F.; Wang, J.; Chen, L. Anal. Chem. 2016, 88, 4122.

[6] Kavok, N. S.; Averchenko, K. A.; Klochkov, V. K.; Yefimova, S. L.; Malyukin, Y. V. Eur. Phys. J. E: Soft Matter Biol. Phys. 2014, 37, 127.

[7] Kim, D.; Kim, G.; Nam, S. J.; Yin, J.; Yoon, J. Sci. Rep. 2015, 5, 8488.

[8] Li, Y.; Li, J.; Li, S.; Li, Y.; Wang, X.; Liu, B.; Fu, Q.; Ma, S. Toxicol. Appl. Pharmacol. 2015, 286, 53.

[9] Zhang, J.; Bao, X.; Zhou, J.; Peng, F.; Ren, H.; Dong, X.; Zhao, W. Biosens. Bioelectron. 2016, 85, 164.

[10] Zhang, J.; Huang, L. L.; Liang, X. J.; Wang, Y.; Duan, N.; Xiang, X. H.; Shu, S. S.; Guo, T. T.; Yang, L.; Tang, X. J. South. Med. Univ. 2016, 36, 833.

[11] Suzuki, N.; Kojima, H.; Urano, Y.; Kikuchi, K.; Hirata, Y.; Nagano, T. J. Biol. Chem. 2002, 277, 47.

[12] Liu, Q.; Xue, L.; Zhu, D. J.; Li, G. P.; Jiang, H. Chin. Chem. Lett. 2014, 25, 19.

[13] Dong, X.; Heo, C. H.; Chen, S.; Kim, H. M.; Liu, Z. Anal. Chem. 2014, 86,308

[14] Vegesna, G. K.; Sripathi, S. R.; Zhang, J.; Zhu, S.; He, W.; Luo, F. T.; Jahng, W. J.; Frost, M.; Liu, H. ACS Appl. Mater. Interfaces 2013, 5, 4107

[15] Wang, M.; Xu, Z.; Wang, X.; Cui, J. Dyes Pigm. 2013, 96, 333.

[16] Feng, W.; Qiao, Q. L.; Leng, S.; Miao, L.; Yin, W. T.; Wang, L. Q.; Xu, Z. C. Chin. Chem. Lett. 2016, 27, 1554.

[17] Wu, C. M.; Chen, Y. H.; Dayananda, K.; Shiue, T. W.; Hung, C. H.; Liaw, W. F.; Wang, Y. M. Anal. Chim. Acta 2011, 708, 141.

[18] Yu, H.; Zhang, X.; Xiao, Y.; Zou, W.; Wang, L.; Jin, L. Anal. Chem. 2013, 85, 7076 .

[19] Ouyang, J.; Hong, H.; Shen, C.; Zhao, Y.; Ouyang, C.; Dong, L.; Zhang, C. Free Radical Biol. Med. 2008, 45, 1426.

[20] Alam, R.; Mistri, T.; Mondal, P.; Das, D.; Mandal, S. K.; Khuda-Bukhsh, A. R.; Ali, M. Dalton Trans. 2014, 43, 2566.

[21] Rout, K. C.; Chaturvedi, S. K.; Khan, R. H.; Mondal, B. Inorg. Chim. Acta 2015, 437, 201.

[22] Chen, L. Y.; Park, J. S.; Wu, D.; Kim, C. H.; Yoon, J. Sens. Actuators, $B$ 2018, 259, 347.

[23] Dai, C. G.; Wang, J. L.; Fu, Y. L.; Zhou, H. P.; Song, Q. H. Anal. Chem. 2017, 89, 10511.

[24] Beltrán, A.; Burguete, M. I.; Abánades, D. R.; Pérez-Sala, D.; Luis, S. V.; Galindo, F. Chem. Commun. 2014, 50, 3579.

[25] Liu, S.; Zhao, J.; Zhang, K.; Yang, L.; Sun, M.; Yu, H.; Yan, Y.; Zhang, Y.; Wu, L.; Wang, S. Analyst 2016, 141, 2296.

[26] Mao, G. J.; Zhang, X. B.; Shi, X. L.; Liu, H. W.; Wu, Y. X.; Zhou, L. Y.; Tan, W.; Yu, R. Q. Chem. Commun. 2014, 50, 5790.
[27] Miao, Z.; Reisz, J. A.; Mitroka, S. M.; Pan, J., Xian, M.; King, S. B. Bioorg. Med. Chem. Lett. 2015, 25, 16.

[28] Liu, C.; Cao, Z.; Wang, Z.; Jia, P.; Liu, J.; Wang, Z.; Han, B.; Huang, X.; Li, X.; Zhu, B.; Zhang, X. Sens. Actuators, B 2015, 220, 727.

[29] Gong, X.; Yang, X. F.; Zhong, Y.; Chen, Y.; Li, Z. Dyes Pigm. 2016, 131,24

[30] Dong, B. L.; Zheng, K. B.; Tang, Y. H.; Lin, W. Y. J. Mater. Chem. B 2016, 4, 1263.

[31] Ali, F.; Sreedharan, S.; Ashoka, A. H.; Saeed, H. K.; Smythe, C. G. W.; Thomas, J. A.; Das, A. Anal. Chem. 2017, 89, 12087.

[32] Li, H.; Yao, Q.; Fan, J; Long, S.; Du, J.; Peng, X. Anal. Chem. 2018, 90, 4641.

[33] Ren, M. G.; Deng, B. B.; Zhou K.; Lin, W. Y. J. Mater Chem. B 2017, 5, 1954.

[34] Dong, B. B.; Song, X. Z.; Kong, X. Q.; Wang, C.; Zhang, N.; Lin, W. Y. J. Mater. Chem. B 2017, 5, 5218.

[35] Jing, X. T.; Yu, F. B.; Chen, L. X. Chem. Commun. 2014, 50, 14253.

[36] Rosenthal, J.; Lippard, S. J. J. Am. Chem. Soc. 2010, 132, 5536.

[37] Wrobel, A. T.; Johnstone, T. C.; Deliz, L. A.; Lippard, S. J.; Rivera-Fuentes, P. J. Am. Chem. Soc. 2014, 136, 4697.

[38] Wrobel, A. T.; Johnstone, T. C.; Deliz Liang, A.; Lippard, S. J.; Rivera-Fuentes, P. Chem. Sci. 2015, 6, 4131.

[39] Sun, X.; Kim, G.; Xu, Y.; Yoon, J.; James, T. D. ChemPlusChem 2016, 81,30

[40] Lv, H. J.; Ma, R. F.; Zhang, X. T.; Li, M. H., Wang, Y. T.; Wang, S.; Xing, G. W. Tetrahedron 2016, 72, 5495.

[41] Pino, N. W.; Davis III, J.; Yu, Z.; Chan, J. J. Am. Che. Soc. 2017, 139, 18476.

[42] Purdey, M. S.; Connaughton, H. S.; Whiting, S.; Schartner, E. P.; Monro, T. M.; Thompson, J. G.; Aitken, R. J.; Abell, A. D. Free Radical Biol. Med. 2015, 81, 69 .

[43] Puskullu, M. O.; Shirinzadeh, H.; Nenni, M.; Gurer-Orhan, H.; Suzen, S. J. Enzyme Inhib. Med. Chem. 2016, 31, 121.

[44] Debowska, K.; Debski, D.; Michalowski, B.; Dybala-Defratyka, A.; Wojcik, T.; Michalski, R.; Jakubowska, M.; Selmi, A.; Smulik, R.; Piotrowski, L.; Adamus, J.; Marcinek, A.; Chlopicki, S.; Sikora, A. Chem. Res. Toxicol. 2016, 29, 735.

[45] Palanisamy, S.; Wu, P. Y.; Wu, S. C.; Chen, Y. J.; Tzou, S. C.; Wang, C. H.; Chen, C. Y.; Wang, Y. M. Biosens. Bioelectron. 2017, 91,849 .

[46] Zhu, B. C.; Wu, L.; Wang, Y.; Zhang, M.; Zhao, Z.; Liu, C.; Wang, Z.; Duan, Q.; Jia, P. Sens. Actuators, B 2018, 259, 797.

[47] Zhou, X.; Kwon, Y.; Kim, G.; Ryu, J. H.; Yoon, J. Biosens. Bioelectron. 2015, 64, 285.

[48] Shen, Y.; Zhang, X.; Zhang, Y.; Li, H.; Dai, L.; Peng, X.; Peng, Z.; Xie, Y. Anal. Chim. Acta 2018, 1014, 71.

[49] Hou, J. T.; Yang, J.; Li, K.; Liao, Y. X.; Yu, K. K.; Xie, Y. M.; Yu, X. Q. Chem. Commun. 2014, 50, 9947.

[50] Sun, C.; Du, W.; Wang, P.; Wu, Y.; Wang, B.; Wang, J.; Xie, W. Biochem. Biophys. Res. Commun. 2017, 494, 518.

[51] Yu, F.; Li, P.; Wang, B.; Han, K. L. J. Am. Chem. Soc. 2013, 135, 7674.

[52] Li, Z. H.; Liu, R.; Tan, Z. L.; He, L.; Lu, Z. L.; Gong, B. ACS Sens. 2017, 2, 501 .

[53] Cheng, D.; Pan, Y.; Wang, L.; Zeng, Z.; Yuan, L.; Zhang, X.; Chang, Y. T. J. Am. Chem. Soc. 2017, 139, 285.

[54] Lin, K. K.; Wu, S. C.; Hsu, K. M.; Hung, C. H.; Liaw, W. F.; Wang, Y. M. Org. Lett. 2013, 15, 4242.

[55] Sun, X.; Xu, Q.; Kim, G.; Flower, S. E.; Lowe, J. P.; Yoon, J.; Fossey, J. S.; Qian, X.; Bull, S. D.; James, T. D. Chem. Sci. 2014, 5, 3368.

[56] Li, H. Y.; Li, X. H.; Wu, X. F.; Shi, W.; Ma, H. M. Anal. Chem 2017, 89, 5519.

[57] Zhu, B. C.; Zhang, M.; Wu, L.; Zhao, Z.; Liu, C.; Wang, Z.; Duan, Q.; Wang, Y.; Jia, P. Sens. Actuators, B 2018, 257, 436.

[58] Wolff, I. A.; Wasserman, A. E. Science 1972, 177, 15. 
[59] Adarsh, N.; Shanmugasundaram, M.; Ramaiah, D. Anal. Chem. 2013, 85, 10008 .

[60] Zhang, J.; Pan, F. C.; Jin, Y.; Wang, N. N.; He, J.; Zhang, W. J.; Zhao, W. L. Dyes Pigm. 2018, 74, 525.

[61] Yan, Y.; Krishnakumar, S.; Yu, H.; Ramishetti, S.; Deng, L. W.; Wang, S. H.; Huang, L.; Huang, D. J. J. Am. Chem. Soc. 2013, 135, 5312.

[62] Chen, J. B.; Li, B.; Xiong, Y. Sens. Actuators, B 2017, 255, 275.

[63] Zuo, L.; Diaz, P. T.; Chien, M. T.; Roberts, W. J.; Kishek, J.; Best, T. M.; Wagner, P. D. PLoS One 2014, 9, e109884.

[64] Zuo, L.; Pannell, B. K.; Re, A. T.; Best, T. M.; Wagner, P. D. Am. J. Physiol.: Cell Physiol. 2015, 309, C759.

[65] Chen, W. C.; Venkatesan, P.; Wu, S. P. New J. Chem. 2015, 39, 6892.

[66] Zang, L.; Liang, C.; Wang, Y.; Bu, W.; Sun, H.; Jiang, S. Sens. Actuators, B 2015, 211, 164.

[67] Wu, G. F.; Zeng, F.; Wu, S. Z. Anal. Methods 2013, 5, 5589

[68] Chen, Y.; Wei, T.; Zhang, Z.; Zhang, W.; Lv, J.; Chen, T.; Chi, B.; Wang, F.; Chen, X. Chin. Chem. Lett. 2017, 28, 1957.

[69] Lv, J.; Chen, Y.; Wang, F.; Wei, T.; Zhang, Z.; Qiang, J.; Chen, X. Dyes Pigm. 2018, 148, 353.

[70] Xi, L. L.; Guo, X. F.; Wang, C. L.; Wu, W. L.; Huang, M. F.; Miao, J. Y.; Zhao, B. X. Senso. Actuators, B 2018, 255, 666.

[71] Sun, M.; Yu, H.; Zhu, H.; Ma, F.; Zhang, S.; Huang, D.; Wang, S. Anal. Chem., 2014, 86, 671.

[72] Xu, J.; Yuan, H.; Qin, C.; Zeng, L.; Bao, G. M. RSC Adv. 2016, 6, 107525.

[73] Xing, P.; Feng, Y.; Niu, Y.; Li, Q.; Zhang, Z.; Dong, L.; Wang, C. Chem.-Eur. J. 2018, 24, 5748.

[74] Sun, M.; Yu, H.; Zhu, H.; Ma, F.; Zhang, S.; Huang, D.; Wang, S. Anal. Chem. 2014, 86, 671.

[75] Song, X.; Dong, B.; Kong, X.; Wang, C.; Zhang, N.; Lin, W. Spectrochim. Acta, Part A 2018, 188, 394.

[76] Zhu, H.; Fan, J.; Wang, J.; Mu, H.; Peng, X. J. Am. Chem. Soc. 2014, 136, 12820.

[77] Xu, Q.; Lee, K. A.; Lee, S.; Lee, K. M.; Lee, W. J.; Yoon, J. J. Am. Chem. Soc. 2013, 135, 9944.

[78] Zhou, J.; Li, L. H.; Shi, W.; Gao, X. H.; Li, X. H.; Ma, H. M. Chem. Sci. 2015, 6, 4884 .

[79] Chen, S. M.; Lu, J. X; Sun, C. D.; Ma, H. M. Analyst 2010, 135, 577.

[80] Jia, J.; Ma, H. M. Sci. Bull. 2011, 56, 3266.

[81] Zhang, Z.; Deng, C.; Meng, L.; Zheng, Y.; Yan, X. Anal. Methods 2015, 7, 107.

[82] Zhang, Z.; Zou, Y.; Deng, C.; Meng, L. Luminescence 2016, 31, 997.

[83] Li, L.; Wang, S.; Lan, H.; Gong, G.; Zhu, Y.; Tse, Y. C.; Wong, K. M. C. ChemistryOpen 2018, 7, 136.

[84] Zhang, Y. R.; Zhao, Z. M.; Su, L.; Miao, J. Y.; Zhao, B. X. RSC Adv. 2016, 6, 17059 .

[85] Shen, S. L.; Ning, J. Y.; Zhang, X. F.; Miao, J. Y.; Zhao, B. X. Sens. Actuators, B 2017, 244, 907.

[86] Zhang, Y. R.; Meng, N.; Miao, J. Y.; Zhao, B. X. Chemistry 2015, 21, 19058.

[87] Zhang, Y. R.; Zhao, Z. M.; Su, L.; Miao, J. Y.; Zhao, B. X. RSC Adv. 2016, 6, 17059 .

[88] Deng, B.; Ren, M.; Kong, X.; Zhou, K.; Lin, W. Sens. Actuators, B 2018, 255, 963 .

[89] Vedamalai, M.; Kedaria, D.; Vasita, R.; Gupta, I. Sens. Actuators, B 2018, 263, 137.

[90] Zhang, B.; Yang, X.; Zhang, R.; Liu, Y.; Ren, X.; Xian, M.; Ye, Y.; Zhao, Y. Anal. Chem. 2017, 89, 10384.

[91] Li, G. P.; Zhu, D. J.; Liu, Q.; Xue, L.; Jiang, H. Org. Lett. 2013, 15, 2002.

[92] Mulay, S. V.; Choi, M.; Jang, Y. J.; Kim, Y.; Jon, S.; Churchill, D. G. Chemistry 2016, 22, 9642.

[93] Mulay, S. V.; Yudhistira, T.; Choi, M.; Kim, Y.; Kim, J.; Jang, Y. J.; Jon, S.; Churchill, D. G. Chem.-Asian J. 2016, 11, 3598.
[94] Chen, P.; Zheng, Z.; Zhu, Y.; Dong, Y.; Wang, F.; Liang, G. Anal. Chem. 2017, 89, 5693.

[95] Shu, W.; Jia, P.; Chen, X.; Li, X.; Huo, Y.; Liu, F.; Wang, Z.; Liu, C.; Zhu, B.; Yan, L.; Du, B. RSC Adv. 2016, 6, 64315.

[96] Pan, Y.; Huang, J.; Han, Y. Tetrahedron Lett. 2017, 58, 1301.

[97] Zhang, P.; Wang, H.; Hong, Y.; Yu, M.; Zeng, R.; Long, Y.; Chen, J. Biosens. Bioelectron. 2018, 99, 318.

[98] Zhang, P.; Wang, H.; Hong, Y.; Yu, M.; Zeng, R.; Long, Y.; Chen, J. Biosens. Bioelectron. 2018, 99, 318.

[99] Li, J.; Yin, C.; Huo, F.; Xiong, K.; Chao, J.; Zhang, Y. Sens. Actuators, $B$ 2016, $231,547$.

[100] Lo, L. C.; Chu, C. Y. Chem. Commun. 2003, 21, 2728.

[101] Chang, M. C. Y.; Pralle, A.; Isacoff, E. Y.; Chang, C. J. J. Am. Chem. Soc. 2004, 126, 15392.

[102] Srikun, D.; Miller, E. W.; Domaille, D. W.; Chang, C. J. J. Am. Chem. Soc. 2008, 130, 4596.

[103] Xu, J.; Li, Q.; Yue, Y.; Guo, Y.; Shao, S. Biosens. Bioelectron. 2014, $56,58$.

[104] Xu, J.; Zhang, Y.; Yu, H.; Gao, X.; Shao, S. Anal. Chem. 2016, 88, 1455.

[105] Zhang, W.; Liu, W.; Li, P.; Huang, F.; Wang, H.; Tang, B. Anal. Chem. 2015, 87, 9825.

[106] Ren, M.; Deng, B.; Zhou, K.; Kong, X.; Wang, J. Y.; Lin, W. Anal. Chem. 2017, 89, 552

[107] Carroll, V.; Michel, B. W.; Blecha, J.; VanBrocklin, H.; Keshari, K.; Wilson, D.; Chang, C. J. J. Am. Chem. Soc. 2014, 136, 14742.

[108] Shen, Y.; Zhang, X.; Zhang, Y.; Wu, Y.; Zhang, C.; Chen, Y.; Jin, J.; Li, H. Sens. Actuators, B 2018, 255, 42.

[109] Li, G.; Zhu, D.; Liu, Q.; Xue, L.; Jiang, H. Org. Lett. 2013, 15, 924.

[110] Qian, Y. Y.; Xue, L.; Hu, D. X.; Li, G. P.; Jiang, H. Dyes Pigm. 2012, 95, 373.

[111] Zhu, D.; Li, G.; Xue, L.; Jiang, H. Org. Biomol. Chem. 2013, 11, 4577.

[112] Zhu, D.; Xue, L.; Li, G.; Che, Y.; Jiang, H. Org. Chem. Front. 2014, 1,501 .

[113] Li, G.; Zhu, D.; Xue, L.; Jiang, H. Org. Lett. 2013, 15, 5020.

[114] Zhu, D.; Xue, L.; Li, G.; Jiang, H. Sens. Actuators, B 2016, 222, 419.

[115] Wu, G.; Zeng, F.; Yu, C.; Wu, S.; Li, W. J. Mater. Chem. B 2014, 2, 8528.

[116] Lim, C. S.; Cho, M. K.; Park, M. Y.; Kim, H. M. ChemistryOpen 2018, 7, 53 .

[117] Zhang, K.; Wu, W.; Li, Y.; Sun, M.; Yu, H.; Wong, M. S. RSC Adv. 2016, 6, 115298.

[118] Gao, C.; Tian, Y.; Zhang, R.; Jing, J.; Zhang, X. Anal. Chem. 2017, 89,12945

[119] Peng, J.; Hou, X.; Zeng, F.; Wu, S. Biosens. Bioelectron. 2017, 94, 278.

[120] Abo, M.; Minakami, R.; Miyano, K.; Kamiya, M.; Nagano, T.; Urano, Y.; Sumimoto, H. Anal. Chem. 2014, 86, 5983.

[121] Reja, S. I.; Gupta, M.; Gupta, N.; Bhalla, V.; Ohri, P.; Kaur, G.; Kumar, M. Chem. Commun. 2017, 53, 3701.

[122] Liao, Y. X.; Li, K.; Wu, M. Y.; Wu, T.; Yu, X. Q. Org. Biomol. Chem. 2014, 12, 3004.

[123] Shanmugapriya, J.; Rajaguru, K.; Sivaraman, G.; Muthusubramanian, S.; Bhuvanesh, N. RSC Adv. 2016, 6, 85838.

[124] Zhuang, Z.; Yang, Q.; Zhang, Z.; Zhang, Q.; Zheng, G.; Zhan, F. J. Photochem. Photobiol., A 2017, 344, 8.

[125] Zhang, K. M.; Dou, W.; Li, P. X.; Shen, R.; Ru, J. X.; Liu, W.; Cui, Y. M.; Chen, C. Y.; Liu, W. S.; Bai, D. C. Biosens. Bioelectron. 2015, 64, 542 .

[126] Yang, Y.; Yang, D.; Yang, D.; Jia, R.; Ding, G. Nephron. Exp. Nephrol. 2014, 128, 30.

[127] Zeng, L.; Xia, T.; Hu, W.; Chen, S.; Chi, S.; Lei, Y.; Liu, Z. Anal. Chem. 2018, 90, 1317.

[128] Bai, X.; Huang, Y.; Lu, M.; Yang, D. Angew. Chem., Int. Ed. 2017, $56,12873$.

[129] Kim, M.; Ko, S. K.; Kim, H.; Shin, I.; Tae, J. Chem. Commun 
2013, 49, 7959.

[130] Lu, D.; Zhou, L.; Wang, R.; Zhang, X.-B.; He, L.; Zhang, J.; Hu, X.; Tan, W. Sens. Actuators, B 2017, 250, 259.

[131] Gao, X.; Feng, G.; Manghnani, P. N.; Hu, F.; Jiang, N.; Liu, J.; Liu, B.; Sun, J. Z.; Tang, B. Z. Chem. Commun. 2017, 53, 1653 .

[132] Zhang, Q.; Zhu, Z.; Zheng, Y.; Cheng, J.; Zhang, N.; Long, Y. T.; Zheng, J.; Qian, X.; Yang, Y. J. Am. Chem. Soc. 2012, 134, 18479.
[133] Sivaraman, G.; Anand, T.; Chellappa, D. ChemPlusChem 2014, 79 , 1761.

[134] Zhang, R.; Zhao, J.; Han, G.; Liu, Z.; Liu, C.; Zhang, C.; Han, M. Y. J. Am. Chem. Soc. 2016, 138, 3769.

[135] Yu, F.; Gao, M.; Li, M.; Chen, L. Biomaterials 2015, 63, 93

[136] Ong, J. X.; Pang, V. Y. T.; Tng, L. M.; Ang, W. H. Chemistry 2018, $24,1870$.

(Zhao, C.) 